\title{
The use of sentinel skin islands for monitoring buried and semi-buried micro-vascular flaps. Part I: Summary and brief description of monitoring methods
}

\author{
Martin Molitora , Ondrej Mestak ${ }^{\mathrm{a}}$, Richard Pink ${ }^{\mathrm{b}}$, René Foltánc , Andrej Sukop ${ }^{\mathrm{d}}$, Stefano Lucchina ${ }^{\mathrm{e}}$
}

\begin{abstract}
Micro-vascular flaps have been used for the repair of challenging defects for over 45 years. The risk of failure is reported to be around $5-10 \%$ which despite medical and technical advances in recent years remains essentially unchanged. Precise, continuous, sensitive and specific monitoring together with prompt notification of vascular compromise is crucial for the success of the procedure. In this review, we provide a classification and brief description of the reported methods for monitoring the micro-vascular flap and a summary of the benefits over direct visual monitoring. Over 40 different monitoring techniques have been reported but their comparative merits are not always obvious. One looks for early detection of a flap's compromise, improved flap salvage rate and a minimal false-positive or false-negative rate. The cost-effectiveness of any method should also be considered.

Direct visualisation of the flap is the method most generally used and still seems to be the simplest, cheapest and most reliable method for flap monitoring. Considering the alternatives, only implantable Doppler ultrasound probes, near infrared spectroscopy and laser Doppler flowmetry have shown any evidence of improved flap salvage rates over direct visual monitoring.
\end{abstract}

Key words: micro-vascular flap, free flap, monitoring methods, sentinel skin paddle, monitoring skin island, buried flap, semi-buried flap

Received: November 8, 2020; Revised: February 22, 2021; Accepted: February 26, 2021; Available online: March 31, 2021 https://doi.org/10.5507/bp.2021.016

(c) 2021 The Authors; https://creativecommons.org/licenses/by/4.0/

${ }^{a}$ Department of Plastic Surgery, First Faculty of Medicine Charles University and Na Bulovce Hospital, Prague, Czech Republic ${ }^{b}$ Department of Maxillofacial Surgery, University Hospital Olomouc and Faculty of Medicine and Dentistry, Palacky University Olomouc, Czech Republic

'Department of Maxillofacial Surgery, General University Hospital and $1^{\text {st }}$ Faculty of Medicine, Charles University, Prague, Czech Republic ${ }^{d}$ Department of Plastic Surgery, University Hospital Kralovske Vinohrady and $3^{\text {rd }}$ Faculty of Medicine, Charles University, Prague, Czech Republic

${ }^{e}$ Hand Unit, General Surgery Department, Locarno's Regional Hospital, Via Ospedale 1, 6600 Locarno, Switzerland

Corresponding author: Martin Molitor, e-mail: martinmolitor1@gmail.com

\section{INTRODUCTION}

The transfer of micro-vascular flaps (MF) in reconstructive surgery is a reliable and well-established method for repairing defects of various aetiology, size and depth. Surgery involving MF however, can be challenging which is sometimes made more so when reliable monitoring is difficult to achieve. The risk of failure of MF is reported to be around $5-10 \%$ (ref. ${ }^{1,2}$ ) and despite developments in techniques, instruments, sutures and devices during the last decades, it remains unchanged ${ }^{3}$. Loss of the flap is still the most significant risk for a patient with the associated consequences; the need for remedial/replacement surgery, additional morbidity of another donor site and prolonging treatment time. From the point of view of the healthcare provider, the increased financial burden is also of prime importance.

The principal complication leading to flap failure is vascular in origin. The patency of micro-vascular anastomoses is crucial for flap viability. When a problem occurs, it is often within the first $48 \mathrm{~h}$ post-surgery. Vascular compromise requiring re-exploration is reported as occurring in $12-17 \%$ of cases ${ }^{4,5}$. Timely detection of a flap vascular problem is very important as about $70-80 \%$ of flaps can be rescued by remedial surgery if done in time ${ }^{6}$. The success of remedial surgery is inversely proportional to the period between the recognition of the complication and the commencement of remedial surgery. Kerrigan et al. in 1984 reported that the tolerated ischemia time of a MF after vascular occlusion is about half of that during primary flap transfer ${ }^{7}$. Logically, earlier detection leads to higher success rates of salvage procedures. It was found that after 1 to $4 \mathrm{~h}$ of ischemia, $100 \%$ of flaps can be salvaged, after 8 hours the success rate decreases to $80 \%$ and after $12 \mathrm{~h}$ all flaps fail ${ }^{4,5,8}$.

Reliable monitoring of the MF blood flow is therefore crucial for early detection of vascular failure leading to prompt revision surgery with a high rate of flap salvage. During the era of micro-vascular reconstructive surgery, about the last 45 years, the first and most widely used 
method of flap evaluation was (and still is) direct visual monitoring (DVM).

Though clearly monitoring is of utmost importance, a survey of units performing MF surgery shows considerable differences in the monitoring methods selected. Currently there is no established or generally accepted standard, algorithm or approach for monitoring the MF. Microsurgical units usually implement DVM with or without some other method, predominantly Doppler ultrasound (DUS) or laser Doppler flowmetry (LDF) (ref. ${ }^{9-11}$ ).

Usually flaps are visible and accessible for DVM. But in maxillofacial surgery, digestive tract reconstruction, vascularised lymph node transfer, long bone restoration and breast or vaginal reconstruction, flaps can be completely buried and DVM is not possible. Flaps used for upper digestive tract reconstruction are "semi-buried"; they are accessible for direct visualisation but with difficulties and their surface is often difficult to evaluate due to saliva maceration ${ }^{12}$. In buried or semi-buried flaps, methods other than DVM must be considered. Another variation that allows DVM in some instances however, is the incorporation of a skin island ${ }^{13-16}$.

A plethora of monitoring techniques have been reported however it is difficult to extract data to find the comparative benefit of particular technique. We suggest the following criteria need to be assessed for informed comparison; (a) salvage rate - that is the ability of a monitoring method to allow early intervention and salvage of a truly compromised flap, (b) false-positive rate - that is the proportion of false positive readings leading to needless re-explorative surgery where the flap was not actually compromised, (c) false-negative rate - which is the proportion of false negative readings that result in flap loss, (d) patient's perception of the monitoring process, and (e) cost-effectiveness. Considering the benefit of more sophisticated methods over DVM we believe, that several issues need to be considered; (a) its reliability and validity, (b) its economic benefit and (c) patient perception and tolerance.

These pieces of information are generally missing or poorly considered in the majority of published works ${ }^{3,17}$.

In this review we have compiled and grouped all reported monitoring methods published to date. We have then classified these methods according to their complexity and then detailed methods that are required to be used where DVM is not possible or efficacious. Also we provide an overview of currently reported monitoring methods and their claimed benefits over DVM after our consideration.

\section{MATERIALS AND METHODS}

We carried out a literature search for the period from 1975-2019 using the bibliography of the database PubMed. Search terms included; free flap monitoring (652 articles), micro-vascular flap monitoring (246 articles), microsurgical flap monitoring (117 articles) and free tissue transfer monitoring (285 articles) totalling 1.300 articles. From this set we excluded (a) duplicate references, (b) references where flap monitoring was peripheral to the topic and (c) invalid or irrelevant references. This left us with 356 valid articles on which to base this review.

As some methods (e.g. Doppler ultrasound and Laser Doppler flowmetry) are used quite routinely and were therefore reported many times in the 356 valid articles we only cited 185 of these in our reference list, selected on the principle that they brought new relevant information to the discussion.

\section{METHODS OF MONITORING THE MICRO-VASCULAR FLAP}

More than 40 methods to monitor flap vascularisation have been reported over the 45-year period of routine MF surgery. The surgeon's intention in every case was to provide a method that would objectively, rapidly and easily provide warning of a compromise event to increase the chance of saving the problematic flap.

There have been many criteria used for classification of monitoring methods. Moubayed ${ }^{18}$ for example made two classes namely; (a) widely used - DVM and Doppler, near-infrared spectroscopy and (b) experimental - all other methods. Schoeller ${ }^{19}$ chose objectivity of the method as the criteria and concluded that his two classes were; (a) subjective - DVM and (b) objective - all the other methods. It is however disputable which methods are truly objective, as some degree of subjective evaluation is often needed in reading and interpreting the findings. In this review we classify monitoring methods according to their complexity as depicted in Table 1.

\section{Direct visual monitoring}

Is subjective yet generally and routinely used and a very reliable method ${ }^{20-26}$. However this is only the case when the flap's surface is at least partially exposed but this is not always true. DVM has the advantage of being the cheapest, simplest and most convenient method of all and can be done by any trained staff (medical, nursing or supportive). It also does not require any special technical additions such as medications, services, facilities or devices.

\section{Non-invasive device-dependent methods}

These encompass a wide variety of methods that use special probes, sensors, cameras, transmitters, microscopes, tomographs and the like. Some of them were reported to have better monitoring capacity than DVM (ref. ${ }^{20,27-30}$ ). However, like DVM they also need the direct access to the flap's surface and are not suitable for buried or semi-buried flap monitoring. They are more demanding of special materials, medications, facilities, devices and often specialised personnel.

\section{Invasive device-dependent methods}

Use implantable equipment that can be placed next to a flap's tissue or pedicle and are therefore able to monitor buried or semi-buried flaps. These methods often 
Table 1. Classification of micro-vascular flap monitoring methods.

\begin{tabular}{|c|c|}
\hline Complexity & Method \\
\hline Device free & $\begin{array}{l}\text { Direct visual monitoring } \\
\text { Bromphenol blue }\end{array}$ \\
\hline $\begin{array}{l}\text { Non-invasive } \\
\text { device-dependent }\end{array}$ & $\begin{array}{l}\text { Surface skin temperature (touch or no-touch) } \\
\text { Doppler ultrasound (handheld) } \\
\text { Pinprick glucose testing } \\
\text { Power Doppler } \\
\text { Tissue harmonic imagingtrade mark } \\
\text { Speckle reduction imagingtrade mark } \\
\text { Laser Doppler flowmetry } \\
\text { Oxygen to See } \\
\text { Confocal laser scanning microscopy } \\
\text { Laser speckle contrast imaging } \\
\text { Visible light spectroscopy } \\
\text { Microlightguide spectrophotometry } \\
\text { Diffuse correlation spectroscopy } \\
\text { Diffuse reflectance spectroscopy } \\
\text { Diffuse correlation spectroscopy/transcutaneous pulse oximetry } \\
\text { Near infrared spectroscopy } \\
\text { Pulse oximetry } \\
\text { Multispectural spatial frequency domain imaging } \\
\text { Luminiscence ratiometric oxygen imaging } \\
\text { Photoplethysmography } \\
\text { Impedance plethysmography } \\
\text { Peroral fluorimetry } \\
\text { Orthogonal polarised light } \\
\text { Compound muscle action potentials } \\
\text { Side-stream dark field imaging } \\
\text { Hydrogen clearance } \\
\text { Contractility/electromyographic activity }\end{array}$ \\
\hline $\begin{array}{l}\text { Invasive } \\
\text { device-dependent }\end{array}$ & $\begin{array}{l}\text { Implantable Doppler probes } \\
\text { Contrast enhanced Doppler } \\
\text { Electromagnetic flowmetry } \\
\text { Implantable spectroscopy probes } \\
\text { Implantable probe pulse oximetry } \\
\text { Intraparenchymatous venous pressure monitoring } \\
\text { Invasive temperature monitoring } \\
\text { Tissue oxygen tension monitoring } \\
\text { Impedance plethysmography } \\
\text { Intravenous fluorimetry }\end{array}$ \\
\hline $\begin{array}{l}\text { Vascular network and } \\
\text { blood flow } \\
\text { visualisation }\end{array}$ & $\begin{array}{l}\text { Classic contrast angiography } \\
\text { Indocyanine-green fluorescence video angiography } \\
\text { Computed tomography angiography } \\
\text { Magnetic resonance imaging angiography }\end{array}$ \\
\hline Nuclear & $\begin{array}{l}\text { Scintigraphy } \\
\text { Positron emission tomography } \\
\text { Radioactive microspheres } \\
\text { Xenon washout method }\end{array}$ \\
\hline Laboratory & $\begin{array}{l}\text { Micro-dialysis } \\
\text { Continuous pH monitoring }\end{array}$ \\
\hline Technical supportive & $\begin{array}{l}\text { Digital photography sharing by Internet } \\
\text { Smartphone applications }\end{array}$ \\
\hline
\end{tabular}

utilise the same principles as non-invasive device dependent methods and can sometimes have better sensitivity than DVM, especially in cases of buried and semi-buried flaps $^{29,31}$. They also require special materials, medications, facilities, devices and specialised staff.

\section{Vascular network and blood flow visualisation}

These are precise methods but are demanding for the patient, the medical staff and require special equipment and facilities. They generally require the transport of the patient to and from a specialised unit. They are suitable for the monitoring of buried and semi-buried flaps, however due to practicality issues they are used very sparingly. They are not suitable for continuous monitoring of MFs ( ref. $^{3}$ ).

\section{Nuclear methods}

These present the same advantages and disadvantage as vascular network visualisations and are used even more 
exceptionally. The superiority of these methods over blood flow visualisation is that they are able to confirm not only blood flow inside the vessels, but also the viability of the flap's tissues ${ }^{32,33}$.

\section{Laboratory methods}

These are complex and evaluate the metabolic changes inside the MF tissues. Though they can be used in all kinds of flaps, they are not utilised routinely as their benefit over other methods is not yet confirmed and are very challenging regarding results interpretation ${ }^{34-37}$.

\section{Technical supportive methods}

These do not introduce any new or inventive methods. They just utilise the Internet and a smartphone with a camera to monitor free flaps remotely using other monitoring methods ${ }^{38-40}$.

In general for monitoring of exposed flaps we can use and more-or-less rely on any of the previously mentioned methods. However this is not the case for buried and semiburied flaps. A summary of the limitations of the monitoring methods is presented in Table 2.

Table 2 specifies the limitations of monitoring methods with respect to the possibility of replacing DVM in the case of buried or semi-buried flaps. Some methods still require access to or even contact with the flap surface. In some methods the penetration of the monitoring stream is limited in depth. Several methods are specific for some kinds of tissue and are therefore not suitable to monitor all flaps but only flaps containing this specific tissue.

\section{BRIEF DESCRIPTION OF MONITORING METHODS}

Direct visual monitoring is subjective and observer dependent but it remains the prevalent method due to its simplicity, cost effectiveness and reliability ${ }^{20-26}$. It has the disadvantage that it requires some degree of experience and there is an initial learning curve for the observer to recognise subtle flap alterations. Naturally this method requires the flap to be entirely or partially exposed. In the case of semi-buried flaps used for upper digestive tract reconstruction, DVM may be possible directly or with the aid of endoscopic or micro-endoscopic techniques ${ }^{12}$.

DVM encompasses a range of tests and observations of colour, surface temperature, turgor/elasticity/consistence, capillary return/refill, blanching time, pinprick / needle stick testing or bleeding after scarification. These characteristics are of course variable and change during the recovery stages. Most microsurgeons would agree that there is no current alternative that entirely supplants DVM. This is because an overall assessment of the flap condition involves consideration of multiple clinical indicators $^{3}$.

Some of the specifics of DVM need to be described in more details.

The colour of flap should be similar to the general skin colour of patient. However, often there is some degree of skin hyperaemia as a reaction to the flap's ischemia time immediately after surgery. We also have to consider that the colour of the recipient region may be somewhat different from that of the donor flap site. Paleness usually indicates ischemia of the flap and a bluish colour may indicate venous congestion ${ }^{26}$. Where a patient is naturally pale skinned, we can enhance skin colour and capillary refill evaluation by inducing a histamine skin reaction. A gentle scarification/irritation of skin causes histaminergic activation by histamine released from skin mast cells. This results in local angioedema characterised by a wheal and flare. The irritated region becomes pinkish/reddish and blanching time is more easily evaluated ${ }^{115}$. However for patients with dark skin, evaluation of the flap skin colour can be difficult or impossible. While it may be true that some skin colour changes occur suddenly, it is often an insidious process that can take 1-2 h to determine. It has been suggested that colour digital photography immediately post-surgery could provide a baseline from which to measure change ${ }^{26,116}$.

The flap turgor should be elastic and soft to the touch. Poor turgor of the flap suggests ischemia while dark oedema indicates venostasis. The elasticity is evaluated by touching and compressing the flap's surface which is a very subjective process. While there are devices available for more objective measurement of skin elasticity (cutometers) we did not find any reference to their use in these procedures.

The flap temperature should be similar to that of the surrounding tissue. It is estimated simply by touching the surface of flap and a control region. This again is very subjective. The flap's surface being relatively cold can indicate ischemia as well as venous congestion. The clinical usefulness of temperature assessment is questionable due to its variability and influence by many external factors $^{26}$. It has also been noted that when the temperature falls significantly, vascular damage is usually irreversible in any case ${ }^{117}$.

Capillary refill time/blanching time is measured by applying gentle pressure usually using some device - spatula or similar for three seconds. A refill time of 3-5 s is considered normal. No blanching or a very slow refill indicates ischemia while a very quick refill suggests venostasis ${ }^{118-120}$. The pressure applied should be gentle to prevent bruising but even when it has occurred, flap survival rate was not affected $^{26,121}$.

The pinprick/needle stick test should not be used routinely as it damages the flap's surface and presents perforation risks even to the point of vascular pedicle damage. This test always causes generalised bruising and mild scaring of the flap's surface. It is usually reserved as a last resort if there is high uncertainty with other clinical findings. Where it is found there is no or very postponed bleeding on testing it suggests an arterial problem. If there is a rapid exit of dark blood, this indicates a venous compromise $^{118}$.

It has been noted when regular DVM was carried out during the first few postoperative days, some units were reporting flap salvage rates of up to $80 \%$ and overall success rates of up to $99 \%$ (ref. ${ }^{17,122-128}$ ). Though many stud- 
Table 2. Limitations of methods for monitoring the buried flaps.

\begin{tabular}{|c|c|c|}
\hline Limitation & Method & Ref. \\
\hline \multirow[t]{23}{*}{ Need for surface exposure or contact } & Direct visual monitoring & $20-26$ \\
\hline & Bromphenol blue & 1,41 \\
\hline & Pinprick glucose testing & 42 \\
\hline & Surface temperature & $43-45$ \\
\hline & Handheld Doppler ultrasound & $46-48$ \\
\hline & Power Doppler & $49-51$ \\
\hline & Contrast enhanced Doppler & $49,52,53$ \\
\hline & Oxygen to see & 54,55 \\
\hline & Laser speckle contrast imaging & 56 \\
\hline & Confocal laser scanning microscopy & 57 \\
\hline & Surface pulse oximetry & $58-61$ \\
\hline & Microlightguide spectrophotometry & 54,62 \\
\hline & Surface diffuse correlation spectroscopy & 63 \\
\hline & Surface diffuse reflectance spectroscopy & 63 \\
\hline & Multispectral spatial frequency domain & $64-66$ \\
\hline & Luminiscence ratiometric oxygen imaging & 67,68 \\
\hline & Photoplethysmography & 69,70 \\
\hline & Fluorimetry & $71-75$ \\
\hline & Orthogonal polarised light & $76-78$ \\
\hline & Technical supportive methods & $38-40$ \\
\hline & Radioactive microspheres & 79,80 \\
\hline & Xenon washout method & 81,82 \\
\hline & Side-stream dark field imaging & 83,84 \\
\hline \multirow[t]{5}{*}{ Limited depth of penetration } & Laser Doppler flowmetry $(8 \mathrm{~mm})$ & $85-88$ \\
\hline & Tissue harmonic imagingtrade mark $(3 \mathrm{~cm})$ & $49-51$ \\
\hline & Speckle reduction imagingtrade mark $(3 \mathrm{~cm})$ & $49-51$ \\
\hline & Visible light spectroscopy ( $8 \mathrm{~mm})$ & $20,89,90$ \\
\hline & Near infrared spectroscopy (10 mm) & $91-95$ \\
\hline Only skin & Luminiscence ratiometric oxygen imaging & 67,68 \\
\hline \multirow[t]{2}{*}{ Only muscle-containing flaps } & Compound muscle action potentials & 96 \\
\hline & Contractility/electromyographic activity & 97 \\
\hline Only muscle and vascularised bone & Tissue oxygen tension & 58,59 \\
\hline Not dark skin and not muscle & Fluorimetry & $71-74,98,99$ \\
\hline \multirow[t]{17}{*}{ Universal not limited } & Probe Doppler ultrasound & 100,101 \\
\hline & Electromagnetic flowmetry & 102,103 \\
\hline & Probe pulse oximetry & $58-61$ \\
\hline & Probe diffuse correlation spectroscopy & 63 \\
\hline & Probe diffuse reflectance spectroscopy & 63 \\
\hline & Intraparenchymatous venous pressure monitoring & 104 \\
\hline & Invasive temperature monitoring & 105 \\
\hline & Impedance plethysmography & 106 \\
\hline & Hydrogen clearance & 109,110 \\
\hline & Classic angiography & 3 \\
\hline & Indocyanine-green fluorescence video angiography & 3,75 \\
\hline & CT angiography & 3 \\
\hline & MRI angiography & 3 \\
\hline & Scintigraphy & 33 \\
\hline & PET using oxygen-15 labelled water & 32,111 \\
\hline & Micro-dialysis & $34,35,112,113$ \\
\hline & pH monitoring & $36,37,114$ \\
\hline
\end{tabular}


ies report the superiority of DVM over other methods, statistically valid clinical trials scientifically confirming its benefits are still absent ${ }^{129}$. However, as DVM is used by all microsurgical units, it is suggested that it should be therefore accepted as the standard against which other methods are compared ${ }^{17,130,131}$.

Skin surface temperature (SST) as a monitor was first reported in 1981 by simply using a thermometer ${ }^{41,43-45}$. This elementary method is not in routine use however, as it was shown, that SST changes were only significant after 15 hours of flap ischemia and that is far too long for successful flap salvage $\mathrm{e}^{117,72}$. Novel, more sensitive methods to detect radiation in the infrared range of the electromagnetic spectrum using no-contact techniques were developed $^{53,132}$. A difference of more than $1.8^{\circ} \mathrm{C}$ between the control and the flap skin was defined as an indicator of an ischemic event. Another retrospective analysis concluded that a decrease greater than $3^{\circ} \mathrm{C}$ is a significant indicator of arterial thrombosis while reduction $1-2{ }^{\circ} \mathrm{C}$ may indicate venous occlusion ${ }^{133}$. Authors concluded the main problem with SST monitoring is that it can fluctuate by as much as $8{ }^{\circ} \mathrm{C}$ depending on clothing, humidity, core temperature, room environment and other variables.

Invasive tissue temperature monitoring utilises two implantable thermocouple probes: distally and proximally from the arterial anastomosis. When arterial or venous thrombosis occurs, reduced blood flow leads to decreased temperature recorded by distal probe. A temperature difference between the probes of more than $0.3^{\circ} \mathrm{C}$ has been advocated as indication for re-explorative surgery ${ }^{105,106}$.

Bromophenol blue is a dye that is injected intravenously and the observer assesses the visible distribution of the dye in the monitored tissue. Should the flap tissue not show the passage of dye it signals arterial obstruction whereas prolonged dye elimination indicates venous compromise. The recommended interval between examinations is $6 \mathrm{~h}$. However the presence of residual dye may confuse interpretation and further, a $6 \mathrm{~h}$ interval is considered too long to provide notice for effective re-explorative surgery ${ }^{1,41}$.

Pinprick glucose testing was suggested as an adjunct to DVM (ref. ${ }^{42}$ ). The authors measured glucose levels with a standard commercial blood glucose monitor used by diabetics and compared the levels found in congested flaps with that of a nearby control area. The study consisted of four MF and two pedicled flaps in total. They found a significantly lower level of glucose in the congested flaps relative to the control areas and postulated that vein occlusion caused pooling of glucose-depleted blood in the tissue.

Doppler ultrasound effect of blood flow in the flap pedicle can be followed indirectly over the skin (surface monitoring using low-frequency continuous-wave ultrasound or colour DUS) or directly with a probe implanted perivascularly (Swartz or Cook system) using a cable or wireless $^{46,47,101,134-138}$. Conventional DUS methods are sensitive for the diagnosis of arterial thromboses, however with venous thromboses, the positive arterial signal can persist for several hours after a venous thrombosis occurs. To remedy this it is suggested the probe is placed on a vein. A greater sensitivity is reported compared with probes used for monitoring arterial flow. A venous Doppler signal instantly detects both venous and arterial flow compromise. A complication arises when monitoring an area with a rich vascular network as it is difficult to be certain that Doppler probe does not provide false positive signals from vessels other than that of the flap's pedicle. This is a more pronounced problem for a handheld probe where it is also difficult to distinguish between an arterial and venous signal. Several comparative studies and meta-analyses demonstrated an increase in the flap salvage rate compared to DVM ( $88 \%$ vs. $66 \%$ ) (ref. $\left.{ }^{8,27-31}\right)$. In the case of buried flaps, clearly an implanted DUS probe facilitates a much better salvage rate than DVM (94\% vs. $40 \%$ ) $\left(\right.$ ref. $\left.^{29}\right)$. The implantable Doppler probes are associated with a small risk of false positives and probe malfunction. This is likely to be due to a learning curve for the surgeons in placing the probe and all medical staff in reading and interpreting the signal ${ }^{100,101,135}$. The DUS seems to be one of the most promising among all techniques other than DVM, especially in buried and semi-buried flaps ${ }^{134}$.

Contrast enhanced ultrasound uses a special ultrasound contrasting agent containing sulfur hexafluoride and has $100 \%$ sensitivity and $86-100 \%$ specificity in predicting flap failure ${ }^{49,52,53}$. The imaging method of contrast-enhanced ultrasound uses the non-linear harmonic parts of the ultrasound waves caused by the contrast agent to provide more resolution. However repeated exposure to intra-venously administered contrast media and the potentially long period between suspicion and examination are the main downfalls of this method.

Another refined ultrasound techniques such as colour coded DUS, cross beamtrade mark and ultrasound computer tomography technique in B-scan have been reported ${ }^{49-51,139}$. Power Doppler is able to detect and assess anastomotic vessels even if they are elongated or twisted. The method is sensitive to low blood flow but is unable to detect flow direction. Tissue harmonic imagingtrade mark offers better contrast and spatial resolution by using the non-linear harmonic portion of ultrasound waves caused by monitored tissue, while speckle reduction imagingtrade mark reduces the grey scale artefacts ${ }^{139}$. Cross beamtrade mark with tissue harmonic imagingtrade mark and speckle reduction imagingtrade mark were used to investigate the peripheral parts of the flaps. These methods were also able to assess the patency of anastomosed vessels and allowed dynamic blood flow monitoring at the microcirculation level to the depth of up to $3 \mathrm{~cm}^{49-51}$. However, only very few studies with a limited number of MF cases were used to evaluate these new methods so further validation is needed to prove reported conclusions.

Laser Doppler flowmetry is used to assess capillary blood flow inside the flaps. The doppler shift of a laser shone into a tissue is used to calculate the speed at which the blood is flowing. The trend of measured perfusion is important rather than the absolute value, especially in case of venous occlusion. A $100 \%$ successful detection rate of vascular compromise was reported ${ }^{85-88,140,141-145}$. LDF can reveal a MF compromise several hours before 
the onset of visual signs. False-positive/negative rates are very low ${ }^{46,47,88}$. LDF poses many characteristics of an ideal monitoring device as it is non-invasive, sensitive, instantaneous and provides continuous data about perfusion ${ }^{20}$. Few studies declared similar salvage rates to DVM alone but one study reported increased salvage rate from $50 \%$ to $85 \%$ (ref. ${ }^{145}$ ). This study was however done on 12 problematic MF cases only ${ }^{85}$. The major limitation of LDF is the depth of penetration ( $8 \mathrm{~mm}$ maximum) that restricts its use in monitoring buried flaps.

Electromagnetic flowmetry permits monitoring of pedicle blood flow. The probe producing an electromagnetic field is placed next to pedicle and measures the electrical potential generated by a column of blood passing through the magnetic field. The intensity of electromagnetic potential is linearly proportional to the intensity of blood flow. A decrease of potential indicates vascular obstruction $^{1,102,103}$.

Oxygen to See utilises the LDF in combination with white light spectrophotometry ${ }^{54}$. The main advantage over simple LDF is that it enables dependable differentiation between venous and arterial occlusion ${ }^{55,147}$. Considerable operator experience is required for reliable interpretation of findings as it's sensitivity is not sufficient to detect low but acceptable perfusion rates early post-operatively and can be incorrectly interpreted to indicate vascular compromise ${ }^{55,146}$. However once flow is established, a downward trend after the second postoperative day indicates the need for re-exploration.

Laser speckle contrast imaging is a camera-based technique that illuminates an area of tissue with divergent $785 \mathrm{~nm}$ light and analyses the interference pattern of the light that is scattered from the tissue. The method is more sensitive than LDF when detecting venous obstruction. However, it requires contact with the MF surface, is very sensitive to motion artefacts and is expensive ${ }^{56}$.

Confocal laser scanning microscopy allows non-invasive, real-time evaluation of tissue microcirculation with a high cellular resolution at the capillary beds of free flaps. The method allows quantitative measurement of blood-cell flow, diameter of the capillary loops and thickness of the epidermis. Venous congestion is characterised by a decrease in blood-cell flow of up to $41 \%$, increasing of the capillary loops diameter up to $22 \%$ and increasing of the epidermis thickness up to $32 \%$ due to oedema and vascular dilatation. By contrast, arterial occlusion is defined by a decrease in blood flow of up to $90 \%$ accompanied by insignificant change of both capillary loop size and epidermal thickness ${ }^{57}$.

Visible light spectroscopy $(V L S)$ uses visible light in real time to measure the haemoglobin saturation at capillary level. Visible light is absorbed by haemoglobin approximately 100 times more than infrared light therefore this technique theoretically should be more sensitive than methods using infrared light. VLS can detect flap ischemia earlier than DVM and an implantable DUS probe but the authors did not report the impact on flap salvage rate $^{89,90}$. The disadvantage of tissue VLS is that it is designed to measure at the depth of cutaneous capillary beds, therefore the readings are non-specific and can re- flect both flap vascular compromise as well as systemic problems like desaturation or hypotension. In its favour, VLS is non-invasive, sensitive, immediate and provides continuous data about flap perfusion so it has potential as an ideal monitoring method ${ }^{20}$. It is however expensive and with a maximum depth of penetration of $8 \mathrm{~mm}$ it limits its use in monitoring buried flaps.

Microlightguide spectrophotometry is a non-invasive method that uses white light from a xenon lamp. Differences between levels of oxyhaemoglobin and deoxyhaemoglobin are measured. Vascular occlusion, both arterial and venous, leads to immediate and massive decreases in haemoglobin oxygenation with increasing of deoxyhaemoglobin values ${ }^{54,61}$.

Diffuse correlation spectroscopy enables the quantification of relative changes in microvascular blood flow. It uses coherent near-infrared light to penetrate tissue while the detector monitors speckle fluctuations in the scattered diffuse light. The speckle signal is modulated by the overall motion of all things that cause scattering in the tissue. The signal modulated by blood cells (predominantly erythrocytes) dominates the spectrum. The probes can be superficial or implantable ${ }^{63}$.

Diffuse reflectance spectroscopy uses a broadband light source to measure tissue vascular oxygenation. Oxygen saturation of blood is calculated as a result of obtaining quantitative values of oxyhaemoglobin, deoxyhaemoglobin and total haemoglobin concentrations using the tissue absorption coefficient. Both diffuse correlation and diffuse reflectance methods provide a portable, non-invasive and inexpensive alternative for microvascular blood flow measurement. Early warning of flap failure was reported ${ }^{63}$.

Multimodal diffuse correlation spectroscopy combined with diffuse reflectance spectroscopy system has been constructed and tested. The measurements were done on the artery, muscle and skin of the MF in a porcine model but only on two animals. A significant inconsistency in obtained measurements was noted and the authors concluded that further development work is needed ${ }^{148,149}$.

Near infrared spectroscopy (NIS) is non-invasive method that measures tissue oxygen saturation and total haemoglobin index using a special probe. It can be used in buried flaps if the overlying tissue is less than $10 \mathrm{~mm}$ thick. The method provides continuous and dynamic monitoring of flaps and is able to distinguish between arterial and venous occlusion which is an advantage over classic pulse oximetry. It is not affected by extrinsic factors, such as blood pressure, perforator size and number etc $^{91}$. The changes in oxygen saturation and total haemoglobin index can precede visual manifestation so near NIS can detect vascular compromise earlier that DVM or even DUS (handheld or implantable probes) (ref. ${ }^{91-95}$ ). Two out of three comparative studies reported statistically significant better flap salvage rates when using NIS together with DVM than when using DVM alone ${ }^{93,94,100,150}$.

Pulse oximetry (PO) estimates real-time oxygen saturation of arterial haemoglobin and follows the difference between decreasing $\mathrm{O} 2$ pressure and increasing $\mathrm{CO} 2$ pressure $^{151,152}$. In detecting flap ischemia the levels of $\mathrm{O} 2$ seem to be more sensitive than $\mathrm{CO} 2$, in venous conges- 
tion it is vice versa ${ }^{153,154}$. $\mathrm{O} 2$ level reacts immediately to changes in microcirculation and can appear several hours earlier than the visual symptoms ${ }^{30,155}$. PO can be utilised transcutaneously or using implantable or transflectance probes $^{58-61}$. Although there are anecdotal reports using PO as a monitoring method, to date there is no valid study to demonstrate PO as having any advantage over DVM (ref. ${ }^{17}$ ).

Multispectral spatial frequency domain imaging is an oxygenation-imaging technique that permits monitoring of tissue oxygenation over a large area. It detects a decrease in oxygen saturation (a result of blood flow obstruction) earlier than visual signs. So far only a limited number of studies have been carried out and mainly in animal models $^{64-66}$.

Luminiscence ratiometric oxygen imaging measures the relative transdermal oxygen consumption between the flap and well perfused normal skin. The operating assumption is that transdermal oxygen consumption of a well-perfused flap should be lower than that of a poorly perfused flap. The method uses a fluorescent oxygen sensory foil with an oxygen reservoir that covers the skin surface of the flap and a handheld fluorescence microscope. It was concluded that a relative consumption of less than 0.3 indicates good flap condition ${ }^{67}$. However this method requires contact with the skin surface and is able to only evaluate the skin condition but not the deeper tissues ${ }^{68}$.

Fluorimetry was used in the 1940s to predict the survival of suspect areas of pedicled flaps and it was found to be accurate. It measures the ultraviolet-induced fluorescence in tissue following intravenous injection of fluorescein dye and renal excretion that represents arterial and venous phases respectively ${ }^{156}$. Introduction of fiberoptic fluorimetry allowed for the monitoring of both perfusion and elimination phases simultaneously, the use of small portion of dye but requests frequent examinations ${ }^{157,73,74}$. Subsequently other studies demonstrated that it is possible to use oral introduction of fluorescein or indocyanine green ${ }^{72,158,159}$. Studies demonstrated this technique to significantly increase the flap salvage rate in comparison with DVM and to be a more specific indicator of flap survival than $\mathrm{pH}$ or SST monitoring ${ }^{71,72,75}$. However the technique has significant disadvantages, namely; a possible allergic reaction to the dye, nursing time demands and inefficacy with dark skin and muscle tissue.

Orthogonal polarised light is relatively new method with no clinical studies performed to date. The technique uses polarised light to determine the microcirculation inside the skin. A special probe emits polarised green light of $548 \mathrm{~nm}$ towards the skin and a certain portion is reflected back. A second polariser filters the reflected light so that only light that has undergone a polarity change due to its interference with haemoglobin caused by Rayleigh scattering can be visualised. Animal studies proved this technique to be accurate in predicting flap necrosis. The use of this method for monitoring of the MF in a clinical setting has been proposed ${ }^{76-78}$.

Compound muscle action potentials can be used to estimate the amplitude, latency, and duration in muscle flaps to assess muscle functional capacity that decreases in the case of ischemia caused by vascular obstruction. The critical values of amplitude changes for vascular compromise are more than $40 \%$ initially and continue decrease thereafter $^{96}$.

Contractility or electromyography (EMG) in response to electrical stimulation was used as an index of muscle viability, i.e., intact circulation. However, contractions as well as EMG potentials could be evoked 1-4 h after blood flow had been arrested. Spontaneous EMG activity, which can be recorded 2-3 weeks after denervation, is affected earlier than muscle excitability; thus, the recording of spontaneous EMG activity may serve as better electrophysiological method for post-operative monitoring of vascularisation in free muscle transfers ${ }^{97}$.

Photoplethysmography (PPG) shines bright light into tissue using a green or infrared light emitting diode. Reflected light from haemoglobin in the dermal capillary red blood cells is detected and analysed as light intensity along a frequency spectrum. PPG directly measures the intensity of reflected light from red blood cells at their reflective wavelength characteristic. This method seems to be able to distinguish between perfused and non-perfused tissues with high sensitivity, specificity and a positive predictive value. The technique is claimed to be much more accurate than LDF as it demonstrates higher correlations to radioactive microsphere results. PPG can be upgraded by using a hand-held computer ${ }^{69,70}$.

Impedance plethysmography uses a small electrode array in which an alternating electric current is passed through a buried free flap. Induced voltage across a small volume is measured. A graphical display of this changing voltage illustrates the pulsatile flow through the flap, enabling continuous assessment of perfusion. The method should be accurate, easily interpreted and therefore suitable for inexperienced staff. It is also able to reveal pedicle obstruction very quickly and to distinguish between arterial and venous blockages ${ }^{107,108}$. The technique is however invasive and no detailed comparative studies have so far been conducted.

Intra parenchymatous venous pressure monitoring uses a special catheter. Change of venous pressure corresponds to arterial or venous thrombosis either by decreasing or increasing respectively. The sensitivity rate was reported to be $86 \%$; specificity rate $96 \%$; positive predictive value rates $64 \%$; negative predictive value rate $99 \%$ and false positive rate $4 \%$. The flap salvage-rate was $83 \%$ in venous thrombosis and $33 \%$ in arterial thrombosis cases ${ }^{104}$.

Tissue oxygen tension measures the pressure gradient between oxygen delivered to the tissue and its actual consumption by mitochondria. This technique presents a sensitive method for detecting circulatory impairment in muscle and bone transfer but is not very reliable for skin bearing or composite flaps ${ }^{58,59}$.

Side-stream dark field imaging is non-invasive method being tested in animal models but rarely in clinical practise yet. It was proposed as a useful monitor in patients with pigmented skin where clinical examination is difficult to assess accurately. The method evaluates end-capillary microcirculation at cellular level using a central light guide that is surrounded by concentrically placed strobo- 
scopic light-emitting diodes to procure side-stream dark field illumination. Real time visualisation of red blood cells and all other cells present in the blood stream is provided. The significant advantage is that this method requires minimal training and it presents a direct measure of blood flow ${ }^{83,84}$.

Hydrogen clearance estimates impedance changes of the tissue because of $\mathrm{H}_{2}$ concentration variations within it. The changes in $\mathrm{H}_{2}$ concentration are registered by electrodes and mathematical analysis of clearance enable quantitative expression of blood flow values in millilitres/ minute/100g of tissue. Limited reports suggest that the method is reliable, simple and is able to detect changes in blood flow earlier than DVM. Also it is possible to distinguish between arterial and venous compromise ${ }^{109,110}$.

Classic angiography, intravenous indocyanine-green fluorescence video angiography, computed tomography (CT) angiography or magnetic resonance imaging (MRI) angiography are methods, which directly visualise anastomoses patency and the vascular network of tissues. These methods are very specific and while providing unique information they are more suited to the research world rather than routine clinical practice due to cost, specialist facilities and staff needed to run them versus the timeliness of the information they can provide ${ }^{3,124}$. These methods also require the application of various contrast agents which present an added risk of allergic reactions and some of them expose the patient to a considerable radiation load. They are certainly not convenient for continuous monitoring ${ }^{3,75}$

Scintigraphy (SG) and Positron emitting tomography (PET) are methods that evaluate special radioactive markers inside tissues after intravascular introduction. Should a vascular pedicle of the flap be compromised, the concentration of markers in the flap tissue is reduced or absent ${ }^{15,32,33,111}$. Isotope techniques are able to show whole flap perfusion and its quantification so they can detect the areas of hypo-perfusion. For SG several isotopes have been studied such as $85 \mathrm{Kr}, 22 \mathrm{Na}, 133 \mathrm{Xe}$ and $99 \mathrm{mTc}$ (ref. ${ }^{33,78,160,161}$ ). PET uses radio-labelled glucose to quantify the metabolic state of tissue or oxygen-15 labelled water to quantify blood flow. Nuclear methods have the same practical disadvantages as mentioned for angiographies, in addition the technique requires a reasonable amount of time between the injection of the radioactive agent and the detection of the isotope inside the tissue. PET however has been considered useful for flap condition assessment in a late postoperative setting ${ }^{162}$.

Radioactive microspheres have been used in an experimental setting to study flap circulation. Intravascular injection of radioactive microspheres leads to their entrapment in tissue to an extent that is proportional to its arterial blood supply. The measured intensity of radiation allows the quantitative approximation of arterial blood supply to be calculated. The method is however not suitable for clinical use as the tissue must be sacrificed and undergo sectioning to carry out the measurement ${ }^{79,80}$.

Xenon washout method uses radio-labelled xenon that is injected intra-dermal. Computer modelling of the decreasing signal as the xenon dissipates from the site provides an indirect determination of blood flow. The method requires manipulation with radioactive material, a sophisticated computing system and is difficult to perform at a patient bedside ${ }^{1,81,82}$.

Laboratory methods offer continuous monitoring of the metabolism in tissue by observing levels of glucose, glycerol, lactate, pyruvate and the lactate/pyruvate ratio, usually using micro-dialysis (MD) provided by a subcutaneously placed double-lumen catheter with a semipermeable membrane. This method detects the metabolic changes following cell damage caused by ischemia. A typical finding is very low glucose concentration, a high lactate/pyruvate ratio and elevation of the lactate concentration ${ }^{35,163}$. Other molecules like complement component 3 (C3) and thromboxane A2 have also been studied ${ }^{164,165}$. MD and rapid sample $M D$ can be useful in cases involving buried flaps and should be able to provide an accurate and objective measure of MF metabolism. By recognising changes in ischemic tissue it should be able to produce early and sensitive warning of flap failure ${ }^{34,35,112}$. The method was tested on a rectus abdominis flap and was reported to be so sensitive that it is able to determine the difference in metabolism between micro-vascular and pedicled flaps and even between zones I and II of pedicled flaps ${ }^{166}$. MD indicates vascular compromise significantly earlier than visual signs ( 5 to $7 \mathrm{~h}$ earlier) with higher specificity but this has been demonstrated on 20 flaps only ${ }^{167}$. A glucose level of less than $3.85 \mathrm{nmol} / \mathrm{L}$ and lactate levels greater than $6.4 \mathrm{mmol} / \mathrm{L}$ indicate pedicle compromise with $98.5 \%$ sensitivity and $99.5 \%$ specificity. Frost reported a superior detection rate in comparison with DVM and DUS and a zero false positive rate ${ }^{31}$. However another study found no benefit of MD over DVM and to the contrary, they found a higher false-positive rate ${ }^{131}$. High specificity and sensitivity has also been reported when monitoring the glucose levels only. It is unproven why the glucose level drops when a vascular pedicle is compromised; it is however logically hypothesised, that decreased or terminated blood flow in a flap leads to depletion of the tissue glucose supply ${ }^{42,113,168-170}$. The major limitation of MD however is its high cost. Continuous $\mathrm{pH}$ monitoring was first introduced in 1983 by using an implantable, removable $\mathrm{pH}$ probe $\mathrm{e}^{36}$. The method has so far not provided reliable diagnosis of vascular thrombosis, but a fall in $\mathrm{pH}$ below 7.30 in the flap or a difference of more than $0.35 \mathrm{pH}$ units between the flap and a control area have been suggested as criteria indicating arterial or venous compromise ${ }^{37,114,171}$. Only a few animal and small clinical pilot studies have been conducted to date and no benefit over other methods has been reported.

Technical support methods utilise a readily accessible Internet and ubiquitous personal smartphones with an inboard camera. This represents an opportunity to monitor $\mathrm{MF}$ at a distance and enable rapid communication between nursing and surgical staff reducing the response time to remedial surgery ${ }^{39}$. Although these support methods do not introduce any new innovative idea, procedure or device, they can have a surprisingly high impact on the overall survival and successful salvage rate of the flap. Two studies reported an improved flap salvage rate from 
$50 \%$ to $100 \%$ and response time-to-action (recognition-tore-explorative surgery) reduced significantly from $75 \mathrm{~min}$ to $24 \mathrm{~min}$ in the first and from $180 \mathrm{~min}$ to $8 \mathrm{~min}$ in the second study ${ }^{172-174}$. Another advantage is to allow efficient examination of a MF for patients distant from their care provider $^{38}$. Eulerian video magnification for non-invasive flap monitoring has also been reported. It is a special technique for enhancing video to reveal nearly invisible changes in colour and motion. One case of monitoring a latissimus dorsi-serratus anterior-rib composite flap was reported with the conclusion that this technique is able to detect changes in perfusion without the clinician needing direct contact with patient. There are significant limitations however, the subject and the camera need to be relatively motionless and adequate lightening (both intensity and rendition) needs to be maintained or reproduced for accurate comparison ${ }^{175}$. Subsequently a smartphone application was developed that enables comparative analysis of digital photography for colour differences and it was reported to have $94 \%$ sensitivity and $98 \%$ specificity in detecting vascular compromise ${ }^{40}$. However this new era of using the Internet and smartphone photography is complicated by possible legal issues around patient-identifiable information and it's storage, transfer, security and ownership rights ${ }^{176}$.

\section{DISCUSSION}

\section{The ideal monitoring method}

Creech defined principal criteria for MF monitoring, stating that an ideal monitoring technique should be:

a) harmless to the patient and flap,

b) rapid, repeatable, reliable, recordable, and rapidly responsive,

c) accurate and inexpensive,

d) objective and applicable to all kinds of flaps,

e) equipped with a simple display that could alert relatively inexperienced personnel to the development of circulatory impairment ${ }^{177}$.

An ideal monitoring technique therefore should be easy to apply, objective, continuous, non-invasive, safe, inexpensive, easily and validly interpreted by medical and nursing staff and cost-effective ${ }^{18,42,177}$. More than 40 monitoring methods have been reported over a 45-year period of using MF's, the first of course being DVM. DVM evaluates multiple specific characteristics, it is simple, cheap, does not require special devices and can be reliably done by any experienced medical staff member. With regular DVM we are able to achieve flap salvage rates up to $80 \%$ and overall success rates of up to $99 \%$ (ref. ${ }^{17,122-128}$ ).

From the collection of reported monitoring methods it is apparent that for monitoring of buried and semi-buried flaps there are only a limited number of methods that are pragmatic. Those are methods that can be used when there is no direct access for DVM. All of them however require special equipment and are of course more expensive. Some of them; angiographies and nuclear medicine methods are moreover not suitable for continuous moni- toring and makes them unlikely to be helpful if salvage is deemed the primary objective of monitoring.

\section{The benefit of other methods over direct visual monitoring}

Many studies had focused on various techniques for monitoring the MF but it is necessary to point out, that the actual purpose of observing the flap viability is to improve the salvage success rate and overall free flap success rate. The crux of the issue therefore is timely and reliable detection of a flap compromise that allows effective explorative surgery leading to salvage of the flap ${ }^{178}$. The reason therefore to explore alternative techniques to DVM is to find a reliable technique in cases where DVM is not possible or to find a technique that delivers a better salvage and overall success rate.

Moubayed however, reported that overall flap success rate in head and neck reconstruction was 95\% whatever monitoring method was used. But the salvage rate ratio (:) to false-positive rate in percentage were 95:0 for near infrared spectroscopy, 81:10 for implantable Doppler and 61.5:0.4 for DVM (ref. ${ }^{18}$ ).

A comprehensive review of studies considering MF monitoring published by Chae in 2015 suggests that:

a) Despite the fact that the flap salvage rate is the most important attribute of a monitoring technique to indicate its value and usefulness, this particular information received the least attention by the authors.

b) There are a few reports claiming that the device used to determine flap circulation compromise, did so earlier than DVM but this statement was not associated with improved flap salvage rates or other objective outcomes.

c) Only a limited number of monitoring techniques have shown any evidence for improvement of flap salvage rates over DVM namely; implantable Doppler probes, near infrared spectroscopy, laser Doppler flowmetry, quantitative fluorimetry and digital smartphone assessments.

d) However none of those studies reached the level of scientific evidence that would enable inclusion for widespread clinical use at that time ${ }^{3}$.

In the Table 3 we summarise the reported benefits of various methods over DVM considering early detection of flap alteration that can lead to successful salvage of a truly compromised flap.

Only Doppler ultrasound, laser Doppler flowmetry and near infrared spectroscopy were reported to produce better salvage rates and the possibility of earlier detection of vascular compromise of the micro-vascular flaps.

Selected methods other than DVM that have been suggested to have the characteristics of an ideal monitoring device are DUS, LDF and VLS. Also many reports claim that some methods determine flap compromise earlier than DVM, however they did not proceed to validate that this leads to improved flap salvage or any other measurable improved outcome. Comprehensive and detailed reviews however suggest that only implantable DUS probes, NIS, LDF, quantitative fluorimetry and smartphone assessments have shown any evidence for improvement of 
Table 3. Monitoring methods and reported benefit over clinical visual assessment.

\begin{tabular}{|c|c|c|}
\hline Monitoring method & Higher salvage rate & Earlier detection \\
\hline Surface skin temperature (surface or implanted) & - & - \\
\hline Bromphenol blue & Not reported & Not reported \\
\hline Pinprick glucose testing & Not reported & Not reported \\
\hline Doppler ultrasound (implantable probes) & + & + \\
\hline Doppler ultrasound (handheld) & Not reported & Not reported \\
\hline Colour Doppler & Not reported & Not reported \\
\hline Contrast enhanced ultrasound & Not reported & Not reported \\
\hline Laser Doppler flowmetry & + & + \\
\hline Electromagnetic flowmetry & Not reported & Not reported \\
\hline Confocal laser scanning microscopy & Not reported & Not reported \\
\hline Laser speckle contrast imaging & Not reported & Not reported \\
\hline Visible light spectroscopy & Not reported & + \\
\hline Microlightguide spectrophotometry & Not reported & Not reported \\
\hline Diffuse correlation spectroscopy & Not reported & Not reported \\
\hline Diffuse reflectance spectroscopy & Not reported & Not reported \\
\hline Near infrared spectroscopy & + & + \\
\hline Pulse oximetry & Not reported & + \\
\hline Multispectural spatial frequency domain imaging & Not reported & + \\
\hline Luminiscence ratiometric oxygen imaging & Not reported & Not reported \\
\hline Fluorimetry & + & Not reported \\
\hline Orthogonal polarised light & Not reported & Not reported \\
\hline Compound muscle action potentials & Not reported & Not reported \\
\hline Contractility/electromyographic activity & Not reported & - \\
\hline Photoplethysmography & Not reported & Not reported \\
\hline Intraparenchymatous venous pressure monitoring & - & Not reported \\
\hline Invasive temperature monitoring & Not reported & Not reported \\
\hline Tissue oxygen tension & Not reported & Not reported \\
\hline Impedance plethysmography & Not reported & Not reported \\
\hline Side-stream dark field imaging & Not reported & Not reported \\
\hline Hydrogen clearance & Not reported & + \\
\hline Angiography & Not reported & Not reported \\
\hline Scintigraphy & Not reported & Not reported \\
\hline Positron emission tomography & Not reported & Not reported \\
\hline Radioactive microspheres & Not reported & Not reported \\
\hline Xenon washout & Not reported & Not reported \\
\hline Micro-dialysis & Not reported & + \\
\hline Glucose-lactate levels & Not reported & + \\
\hline Continuous $\mathrm{pH}$ monitoring & Not reported & Not reported \\
\hline Digital photography / camera & Not reported & + \\
\hline
\end{tabular}

flap salvage rates over DVM. None of the reports of the aforementioned methods however reached the level of statistical validity that would enable a particular technique to be approved for widespread clinical use $\mathrm{e}^{3,39,54,89,90,94,95,167,172}$. Mostly the studies report some benefit of a new method however about $50 \%$ of studies also report adverse findings such as additional expenses, technical/training issues and misdiagnoses leading to poorer outcomes overall ${ }^{176}$.

Current general clinical practise is to monitor nonburied flaps by DVM usually supported by one other method; DUS (most often), LDF, spectroscopy or plethysmography ${ }^{3,179}$. Simultaneous use of two methods however presents a surgical dilemma when there is disagreement between the indications of each method. For buried and semi-buried flaps the most units utilise an implantable DUS probe. However, the disadvantage of devices using implantable probes is that even minor movement of the device within the patient alters the signal so they are more prone to give false results due to simple probe displacement or technical failure. Also there is a risk of inadvertent premature probe removal or unwanted forces on anastomoses by the transduction wire or probe that can lead to vessel kinking or compression ${ }^{20}$. Another option for buried flaps evaluation is the use of an externalised part of the flap as visual monitor - skin, muscle or other. This technique is feasible in almost all kinds and types of MF and enables one to use all the advantages of DVM with or without implementation of other methods.

\section{The optimal monitoring frequency}

The optimal frequency of MF monitoring is unclear and is not generally defined nor is there an accepted 
standard. It is highly variable and often it is adapted to individual patient/surgery conditions, surgeon experience or surgical unit historical routine use. However multiple recommendations were reported during last decades. The British Association of Head and Neck Oncology Nurses recommends for routine non-complicated cases monitoring every $15 \mathrm{~min}$ for the first $6 \mathrm{~h}$, then $30 \mathrm{~min}$ for the next $18 \mathrm{~h}$, hourly for the next $48 \mathrm{~h}$ and then individually ${ }^{119}$. Another recommended schedule is hourly monitoring by nursing staff for the first $48 \mathrm{~h}$ and then 2-hourly simultaneously with medical monitoring every $4 \mathrm{~h}$ for first $48 \mathrm{~h}$ and then 8-hourly ${ }^{118,180}$. Chae advocated half-hourly for the first $24 \mathrm{~h}$, hourly for the next $24 \mathrm{~h}, 2$-hourly for the next $24 \mathrm{~h}$ and 4-hourly thereafter ${ }^{3}$. Yet another protocols advise hourly monitoring for first $72 \mathrm{~h}^{120,180}$. Zoccali recommend hourly evaluation for the first $48 \mathrm{~h}$ and then it be reduced to 6 hourly $^{5}$. In our department the routine protocol for standard non-complicated cases is monitoring hourly for first 3 days and then 4 hourly until the patient is dismissed (usually 7-10 days after surgery).

\section{The optimal monitoring period}

Zoccali et al. reported, that when flap discomfort occurs more than 48 hours after surgery the salvage procedure usually fails. He concluded that late flap compromise is more likely due to some flap-internal failure rather than that of vascular pedicle origin and attempted salvage surgery may not be worthwhile. Therefore he proposed that monitoring of the MF is very important during the first two days and the salvage surgery should be carried out whenever there is a suspicion in this timeframe. However continuing monitoring past this point is debatable as reexploration should be considered prudently ${ }^{5}$. Another authors support this thesis ${ }^{26}$. They suggest the first 72 $\mathrm{h}$ after free flap surgery is the critical period. Arterial occlusion occurs usually within first $24 \mathrm{~h}$, venous congestion between 24-72 h. There is little evidence supporting continued MF monitoring after the initial three days.

\section{Patient's perception of flap monitoring}

Creech's criteria for an optimal monitoring method states that; it should be harmless to the patient and the flap ${ }^{177}$. However, we need to consider not only the physical safety of patient but also their psychological comfort and acceptance. Significant patient distress can lead to consequences at the microcirculatory level ending with vascular spasms. This was proved in coronary arteries and can be applied to other vessels too ${ }^{181}$. Spasm of vascular pedicle can of course result in thrombosis especially at the site of anastomosis.

A questionnaire-based study concludes that generally patients are not worried by observation but about $30 \%$ reported disturbed sleep and $50 \%$ would appreciate fewer observations when asleep ${ }^{182}$. Again about 50\% feel relief when the monitoring changes from hourly to four-hourly. Saldago et al confirmed that frequent periodical flap monitoring that is usual within few first days after surgery can be distressing and in predisposed persons can lead to psychological discomfort with possible consequences in flap circulation alteration ${ }^{183}$.

\section{The financial aspects of monitoring}

The clinical benefit of various methods of MF monitoring is crucial and is the prime focus of published studies. However, financial aspects are becomingly increasingly important as there is more competition for resources and the cost of sophisticated equipment and specialist operators increases. In 1975 Creech suggested that the ideal monitoring method should be selected using benefit to the patient as the only criteria ${ }^{177}$. However in 2010 Sakakibara and then in 2016 Moubayed reported that cost effectiveness should also be taken into account ${ }^{18,42}$. It is generally accepted that the worlds public healthcare systems are becoming more and more financially demanding and funds needed to cover medical care are increasing rapidly. A major contributor to this is new and expensive technologies implemented in medicine to deliver better outcomes.

The cost of each method can be broken down into direct and indirect expenses. Direct expenses include special equipment (probes, transmission wires, monitors, cameras, computers, ultrasounds, lasers, laboratory or other devices and the like) and general consumables (gloves, swabs, syringes, needles, sutures, disinfection solutions, ultrasound gel, reagents etc.) Indirect expenses are more difficult to estimate precisely and are also challenging to discover in total. They include but are not limited to such things as staff costs, power costs, expenses related creating and running specialised units or laboratories, building of special facilities or updating existing facilities to comply with progressing safety standards, services and calibrations of machines but also things like phone calls, Internet, costs of special smartphone applications etc.

A financial costing of a proposed method is however rarely reported. Generally where there is some consideration, only direct expanses are mentioned. For example the cost of one tissue oximeter single use implantable probe is about 600 USD, the cost of a colour Doppler ultrasonography machine is between $30.000-225.000$ USD $\left(\right.$ ref. $^{20}$ ). Looking at direct expenses only for DVM, the initial outlay is near 0 USD and per patient are near 0 USD, for handheld Doppler costs are initially100 USD and $0 /$ patient, for implantable Doppler initially 3.100 USD and 400/patient and for near infrared spectroscopy initially 19.500 USD and 650/patient ${ }^{18}$. Poder in 2013 estimated the personnel costs per flap using an implantable Doppler were approximately $200 \mathrm{CAD}$ (ref. ${ }^{184}$ ). In 2015 Chae reported the total cost for micro-dialysis to be about 597 USD/patient ${ }^{3}$.

In our search, we found only one comprehensive paper related to cost-effectiveness of MF monitoring and it only considers DVM. The cost of DVM in 2016 has been calculated to be 193AUD per case considering staff time, equipment and materials. The authors calculated the costs of a salvage procedure as 1.015 AUD per hour and the costs of a replacement surgery as 5.075 AUD. When considering total cost-effectiveness the study revealed an alarming outcome. DVM of all the evaluated flaps totalled 25.476 AUD and did not lead to the successful salvage of a single MF (ref. ${ }^{185}$ ). They performed hypothetical calculations using a base of $400 \mathrm{MF}$ 's with or without monitoring and assumed two regimes, firstly a salvage rate of $60 \%$ and 
failure rate of $7.5 \%$ and secondly a salvage rate of $60 \%$ and failure rate of $0.7 \%$. This resulted in the overall costs for 400 monitored flaps being higher than for 400 flaps without monitoring just simple replacement of necrotic flaps in both regimes.

When considering the cost-effectiveness of any monitoring method it must clinically or economically improve or beneficially change the outcome in some way. Should the failure rate of MF be zero, monitoring is neither costeffective nor beneficial. It follows logically, that monitoring can be cost-effective only when there is quite a high frequency of vascular failure and the outcome of monitoring is maximal salvage success rate and minimal replacement surgery. In general, the rate of MF compromise or loss is relatively low and therefore blanket monitoring of all MF's cannot be cost-beneficial even when using simple DVM. This might lead us to conclude that we should consider selective use of monitoring only in high-risk patients or technically difficult flaps. There are however two reasons why this is not possible; (a) there is a wide spectrum of causes of MF failure and some of them are surgeonindependent and (b) there are no reliable criteria on how to define a true high-risk patient or MF from the point of view of MF failure. However, it has been suggested, that a way to diminish the financial burden is to reduce the frequency and longevity of flap monitoring ${ }^{5,26}$.

In general we have yet to accept that the principal benefit of universal monitoring of the MF is psychological for both staff and patient and that by monitoring all MFs, we are able to detect flap compromise with a successful salvage procedure in some cases, that no doubt is highly beneficial for that particular patient.

\section{CONCLUSION}

The use of MF has been a clinical reality for over 45 years and currently it is a well-established method that is applicable to a wide range of reconstructive cases. Despite the continuing refinement of microsurgical techniques and the ongoing development of devices and materials, some failures of the MF are likely to occur. In the last decade, the rate of re-operation and flap loss of $5-10 \%$ remains basically unchanged. This is because there is a wide array of factors that are responsible for flap failure and some of them are impossible to eliminate and are far beyond the control of the surgeon. However, there are still complications that can be reversed by re-explorative surgery when it is implemented in an appropriate time frame. This highlights a real need for reliable continuous monitoring of free flaps.

Over 40 methods of MV monitoring have been presented during the 45 -year history. The ideal monitoring method was defined as (a) harmless to the patient and flap, (b) rapid, repeatable, reliable, recordable, and rapidly responsive, (c) accurate and inexpensive, (d) objective and applicable to all kinds of flaps, (e) equipped with a simple display that could alert relatively inexperienced personnel to the development of circulatory impairment and (f) cost-effective.
DVM is still generally used and accepted as a standard, easy to perform and reliable method. It evaluates the actual flap condition and the dynamics of changes. The reason for inventing and testing any new method should be to find a reliable technique in cases where direct visualisation is not possible or to find a technique that is more reliable and offers better salvage and overall success rates. Though some methods are considered to be ideal as they are non-invasive, simple, relatively inexpensive, specific and easily evaluated by medical and nursing staff, valid scientific evidence supporting their superiority over DVM is still missing. A further concern is the financial impact of monitoring methods on an already increasingly cost conscious healthcare system. Although in human medicine, cost-benefit is generally not considered as the highest priority, financial consequences are becoming more and more pronounced.

In clinical settings, usually microsurgical units implement DVM alone or with some supporting method such as DUS, LDF, plethysmography or spectroscopy. For buried flaps, handheld DUS or an implantable DUS probe is used.

To date, there is no alternative that can entirely supplant DVM. The effectiveness of DVM can be potentiated using any of the technical support methods referred to above. In this review, we find that there is a persistent belief that DVM possesses optimal characteristics - balanced effectiveness, safety and costs. For these reasons, we conclude that for buried and semi-buried flaps use of an externalised part of the flap as monitor is highly advocated.

\section{Search strategy and selection criteria}

Our search strategy was to collect all reported methods of monitoring of micro-vascular flaps and to evaluate their benefits over the simple and generally used direct visual monitoring. Scientific articles from 1975-2019 were searched using the PubMed database and we found 1.300 pertinent articles. Search terms included; free flap monitoring, micro-vascular flap monitoring, microsurgical flap monitoring and free tissue transfer monitoring. Exclusion criteria were (a) duplicate references, (b) references where flap monitoring was peripheral to the topic and (c) invalid or irrelevant references. After applying the exclusion criteria we were left with 356 valid articles on which this review is based.

\section{ABBREVIATIONS}

MF, Micro-vascular flap; DVM, Direct visual monitoring; LDF, Laser Doppler flowmetry; SST, Skin surface temperature; DUS, Doppler ultrasound; VLS, Visible light spectroscopy;, NIS, Near infrared spectroscopy; PO, Pulse oximetry; EMG, Electromyography; PPG, Photoplethysmography; CT, Computed tomography; MRI, Magnetic resonance imaging; SG, Scintigraphy; PET, Positron emitting tomography; MD, Micro-dialysis. 
Author contributions: All authors contributed equally to preparing the manuscript.

Conflict of interest statement: The authors state that there are no conflicts of interest regarding the publication of this article.

\section{REFERENCES}

1. Buncke HJ, Lineaweaver W, Valauri F, Buncke GH. Chapter $37-$ Monitoring. In: Buncke HJ, eds. Microsurgery transplantation-replantation. Philadelphia: Lea \& Febiger 1991:715-21.

2. Spiegel JH, Polat JK. Microvascular flap reconstruction by otolaryngologists; prevalence, postoperative care, and monitoring techniques. Laryngoscope 2007;117:485-90.

3. Chae MP, Rozen WM, Whitaker IS, Chubb D, Grinsell D, Ashton MW, Hunter-Smith DJ, Lineaweaver WC. Current Evidence for Postoperative Monitoring of Microvascular Free Flaps. A Systematic Review. Annals of Plastic Surgery 2015;74:621-32.

4. Khatri N, Zhang S, Kale SS. Current Techniques for Postoperative Monitoring of Microvascular Free Flaps. J. Wound Ostomy Continence Nurs 2017;44:148-52.

5. Zoccali G, Molina A, Farhadi J. Is long-term Post-operative monitoring of microsurgical flaps still necessary? J Plast Reconstr Surg 2017;70:996-1000.

6. Disa JJ, Cordeiro PG, Hidalgo DA. Efficacy of conventional monitoring techniques in free tissue transfer: an 11-year experience in 750 consecutive cases. Plast Reconstr Surg 1999;104:97-101.

7. Kerrigan $\mathrm{CL}$, Zelt RG, Daniel RK. Secondary critical ischaemia time for experimental skin flaps. Plast Recostr Surg 1984;74:522-6.

8. Clinton MS, Sepka RS, Bristol LD, Pederson WC, Borwick WJ, Serafin D, Klitzman B. Establishment of normal ranges of laser Doppler blood flow in autologous tissue transplants. Plast Reconstr Surg 1991;87:299-309.

9. Bellamy JL, Mundinger GS, Flores JM, Wimmers EG, Yalanis GC, Rodriguez ED, Sacks JM. Do adjunctive flap-monitoring technologies impact clinical decision making? An analysis of microsurgeon preferences and behaviour by body region. Plast Reconstr Surg 2015;135:883-92.

10. Jallali N, Ridha H, Butler PE. Postoperative monitoring of free flaps in UK plastic surgery units. Microsurgery 2005;25:469-72.

11. Durnig $P$, Meier M, Reichert B. Monitoring of free flaps and replantation. Status quo in German-speaking microsurgery units. Handchir Mikrochir Plast Chir 2008;40:392-9.

12. Upile T, Jerjes W, El Maaytah M, Hopper C, Searle A, Wright A. Direct microvascular monitoring of a free autologous jejunal flap using microendoscopy: a case report. BMC Ear, Nose and Throat Disorders 2006;6:14-9.

13. Agarwal JP, Agarwal S, Adler N, Gottlieb LJ. Refining the intrinsic chimera flap: a review. Ann Plast Surg 2009;63:462-7.

14. Laporta R, Longo B, Sorotos M, Pagnoli M, Di Pompeo FS. DIEP flap sentinel skin paddle positioning algorithm. Microsurgery 2015;35:91-100.

15. Pellini R, Pichi B, Ruggieri M, Ruscito P, Spriano G. Venous flowthrough flap as an external monitor for buried radial forearm free flap in head and neck reconstruction. J Plast Reconstr Aesthet Surg 2006;59:1217-21.

16. Yoshimura M, Shimamura K, Iwai Y, Yamauchi S, Ueno T. Free vascularised fibular transplant. A new method for monitoring circulation of the grafted fibula. J Bone Joint Surg Am 1983;65:1295-301.

17. Chubb D, Rozen WM, Whitaker IS, Acosta R, Grinsell D, Ashton MW. The efficacy of clinical assessment in the postoperative monitoring of free flaps: a review of 1140 consecutive cases. Plast Reconstr Surg 2010;125:1157-66.

18. Moubayed SP, Mourad M, Urken ML. What Are the Optimal Monitoring Techniques in Head and Neck Microvascular Reconstruction? ORL J Otorhinolaryngol Relat Spec 2016;78:241-4.

19. Schoeller T, Ninkovic M, Wechselberger G. A simple method of free-flap monitoring using a superficial vein. J Reconstr Microsurg 1996;12:371-3.

20. Chao AH, Meyerson J, Povoski SP, Kocak E. A review of devices used in the monitoring of microvascular free tissue transfers. Expert Rev Med Devices 2013;10:649-60.
21. Imran Y, Zulmi W, Halim AS. Skin paddle as an indicator for the viability of vascularised fibular graft. Singapore Med J 2004;45:110-2.

22. Ferguson RE, Yu P. Techniques of Monitoring Buried Fasciocutaneous Free Flaps. Plast Reconstr Surg 2009;123:525-32.

23. Cervenka B, Bewley AF. Free flap monitoring: a review of the recent literature. Curr Opin Otolaryngol Head Neck Surg 2015;23:393-8.

24. Kääriäinen $M$, Halme $E$, Laranne J. Modern postoperative monitoring of free flaps. Curr Opin Otolaryngol Head Neck Surg 2018;26:248-53.

25. Pellini R, Pichi B, Marchesi P, Cristalli G, Deganello A Spriano G. External monitor for buried free flaps in head and neck reconstructions. Acta Otorhinolaryngol Ital 2006;26:1-6.

26. Shakib K, Newman L, Kalavrezos N. Practical free flap monitoring techniques in head and neck surgery. Br J Hospit Med 2009;70:505-9.

27. Kind GM, Buntic RF, Buncke GM, Cooper TM, Siko PP, Buncke HJ Jr. The effect of an implantable Doppler probe on the salvage of microvascular tissue transplants. Plast Reconstr Surg 1998;101:1268-73; discussion 1274-5

28. Rozen WM, Chubb D, Whitaker IS, Acosta R. The efficacy of postoperative monitoring: a single surgeon comparison of clinical monitoring and the implantable Doppler probe in 547 consecutive free flaps. Microsurgery 2010;30:105-10.

29. Schmulder A, Gur E, Zaretski A. Eight-year experience of the Cook-Swartz Doppler in free-flap operations: microsurgical and reexploration results with regard to a wide spectrum of surgeries. Microsurgery 2011;31:1-6.

30. Smith A, Sonneveld J, Kort W, van der Meulen J. Clinical application of transcutaneous oxygen measurements in replantation surgery and free tissue transfer. J Hand Surgery 1983;8:139-45.

31. Frost MW, Niumsawatt V, Rozen WM, Eschen GE, Damsgaard TE, Kill BJ. Direct comparison of postoperative monitoring of free flaps with microdialysis, implantable cook-Swartz Doppler probe, and clinical monitoring in 20 consecutive patients. Microsurgery 2014;35:26271.

32. Schrey A, Niemi T, Kinnunen I, Minn H, Vahlberg T, Kalliokoski K, Suominen E, Grénman R, Aitasalo K. The limitations of tissue-oxygen measurement and positron emission tomography as additional methods for postoperative breast reconstruction free-flap monitoring. J Plast Reconstr Aesthet Surg 2010;63:314-21.

33. Schuepbach J, Dassonville O, Poissonet G, Demard F. Early postoperative bone scintigraphy in the evaluation of microvascular bone grafts in head and neck reconstruction. Head and Neck Medicine 2007;3:20-6.

34. Allen WN, King A, Blackburn TK. Microdialysis monitoring of a craniofacial microvascular free flap reconstruction detected critical brain swelling. Br J Neurosurg 2013;27:701-3.

35. Nielsen HT, Gutberg N, Birke-Sorensen H. Monitoring of intraoral free flaps with microdialysis. Br J Oral Maxillofac Surg 2011;49:521-6.

36. Raskin DJ, Erk Y, Spira M, Melissinos EG. Tissue pH monitoring in microsurgery: a preliminary evaluation of continuous tissue $\mathrm{pH}$ monitoring as an indicator of perfusion disturbances in microvascular free flaps. Ann Plast Surg 1983;11:331-9.

37. Warner KG, Durham-Smith G, Butler MD, Attinger CE, Upton J, Khuri SF. Comparative response of muscle and subcutaneous tissue $\mathrm{pH}$ during arterial and venous occlusion in musculocutaneous flaps. Ann Plast Surg 1989;22:108-16.

38. Alemi AS, Seth R, Heaton C, Wang SJ, Knott PD. Comparison of Video and In-person Free Flap Assessment following Head and Neck Free Tissue Transfer. Otolaryngol Head Neck Surg 2017;156:1035-40.

39. Chen HC, Kuo HC, Chung KP, Chen SH, Tang YB, Su S. Quality improvement of microsurgery through telecommunication-the postoperative care after microvascular transfer of intestine. Microsurgery 2012;32:96-102.

40. Kiranantawat K, Sitpahul N, Taeprasartsit P, Constanstidines J, Kruavit A, Srimuninnimit V, Punyahotra N, Chatdokmaiprai C, Numhom S. The first Smartphone application for microsurgery monitoring:SilpaRamanitor. Plast Reconstr Surg 2014;143:130-9.

41. Goulian D Jr. The use of bromphenol blue in the assay of rheomacrodex effects on flap viability. Plast Reconstr Surg 1967;39:227-33.

42. Sakakibara $S$, Hashikawa $K$, Omori $M$, Terashi $H$, Tahara S. A simplest method of flap monitoring. J Reconstr Microsurg 2010;26:433-4.

43. Harrison DH, Girling M, Mott G. Experience in monitoring the circulation in free-flap transfers. Plast Reconstr Surg 1981;68:543-55.

44. Harrison DH, Girling M, Mott G. Methods of assessing the viability of free flap transfer during the postoperative period. Clin Plast Surg 1983;10:21-36. 
45. Khouri RK, Shaw WW. Monitoring of free flaps with surface-temperature recordings: Is it reliable? Plast Recostr Surg 1992;89:495-9.

46. Jones BM, Greenhalgh, RM. The use of the ultrasound Doppler flowmeter in reconstructive microvascular surgery. Br J Plast Surg 1983;36:245-53.

47. Jones BM, Mayou BJ. The Laser Doppler flowmeter for microvascular monitoring: a preliminary report. Br J Plast Surg 1982;35:147-9.

48. Solomon GA, Yaremchuk MJ, Manson PN. Doppler ultrasound surface monitoring of both arterial and venous flow in clinical free tissue transfers J Reconstr Microsurg 1986;3:39-41.

49. Lamby P, Prantl L, Gais S, Walter M, Bachthaler M, Nerlich M, Feuerbach $S$, Jung EM. Evaluation of the vascular integrity of free flaps based on microcirculation imaging techniques. Clin Hemorheol Microcirc 2008;39:253-63.

50. Prantl L, Pfister K, Kubale R, Schmitt S, Stockhammer V, Jung W, Zorger N, Herold T, Nerlich M, Stehr A, Jung EM. Value of high resolution ultrasound and contrast enhanced US pulse inversion imaging for the evaluation of the vascular integrity of free-flap grafts. Clin Hemorheol Microcirc 2007;36:203-16.

51. PrantI L, SchremI S, Walter M, Kasprzak P, Stehr A, Nerlich M, Feurbach $\mathrm{S}$, Jung EM. Evaluation of microcirculation of free flaps of the lower leg by contrast harmonic imaging $(\mathrm{CHI})$ with time intensity curve (TIC) analysis. Clin Hemorheol Microcirc 2008;39:343-50.

52. Geis S, Prantl L, Mueller S, Gosau M, Lamby P, Jung EM. Quantitative assessment of bone microvascularisation after osteocutaneous flap transplantation using contrast-enhanced ultrasound (CEUS). Ultraschall Med 2013;34:272-9.

53. Sharma S, Anand R, Hickman M, Senior R, Walji S, Ramchandani PL, Culliford D, llankovan V, Greaves K. Power modulation contrast enhanced ultrasound for postoperative perfusion monitoring following free tissue transfer in head and neck surgery. Int J Oral Maxillofac Surg 2010;39:1211-7.

54. Holzle F, Loeffelbein DJ, Nolte D, Woll KD. Free flap monitoring us ing simultaneous non-invasive laser Doppler flowmetry and tissue spectrophotometry. J Craniomaxillofac Surg 2006;105:55-61.

55. Mucke T, Wolff KD, Rau A, Kehl V, Mitchell DA, Steiner T. Autonomisation of free flaps in the oral cavity: A prospective clinical study. Microsurgery 2012;32:201-6.

56. Zötterman J, Bergkvist M, Iredahl F, Tesselaar E, Farnebo S Monitoring of partial and full venous outflow obstruction in a porcine flap model using laser speckle contrast imaging. J Plast Reconstr Aesthet Surg 2016;69:936-43.

57. Altintas MA, Altintas AA, Guggenheim M, Knobloch K, Niederbichler $A D$, Vogt PM. Monitoring of microcirculation in free transferred musculocutaneous latissimus dorsi flaps by confocal laser scanning microscopy--a promising non-invasive methodical approach. J Plast Reconstr Aesthet Surg 2010;63:111-7.

58. Hirigoyen MB, Blackwell KE, Zhang WX, Silver L, Weinberg H, Urken ML. Continuous tissue oxygen tension measurement as a monitor of free-flap viability. Plast Reconstr Surg 1997;99:763-73.

59. Serafin D, Lesesne CB, Mullen RY, Georgiade NG. Transcutaneous PO2 monitoring for assessing viability and predicting survival of skin flaps: experimental and clinical correlations. J Microsurg 1981;2:16578.

60. Mahoney JL, Lista FR. Variations in flap blood flow and tissue PO2: a new technique for monitoring flap viability. Ann Plast Surg 1988;20:43-7.

61. Lindsey LA, Watson JD, Quaba AA. Pulse oximetry in postoperative monitoring of free muscle flaps. Br J Plast Surg 1991;44:27-9.

62. Wolff KD, Marks C, Uekermann B, Specht M, Frank KH. Monitoring of flaps by measurement of intracapillary haemoglobin oxygenation with EMPHO II: experimental and clinical study. Br J Oral Macillofac Surg 1996;34:524-9.

63. Kolodziejski NJ, Stapels CJ, McAdama DR, Fernandes DE, Podolsky MJ, Farkas D, Ward BB, Vartarian M, Feinberg SE, Lee SY, Parikh U, Mycek MA, Christian JF. A compact instrument to measure perfusion of vasculature in transplanted maxillofacial free flaps. Proc SPIE Int Soc Opt Eng 2016;9715:97150L.

64. Rimler J, Ponticorvo A, Taydas E. A Critical Evaluation of Human Perception in Conventional Flap Monitoring Versus Spatial Frequency Domain Imaging. Plast Reconstr Surg 2014;134(4S-1Suppl):73.

65. Gioux S, Mazhar A, Lee BT, Lin SJ, Tobias AM, Cuccia DJ, Stockdale A, Oketokoun R, Ashitate Y, Kelly E, Weinmann M, Durr NJ, Moffitt LA, Durkin AJ, Tromberg BJ, Frangioni JV. First-in-human pilot study of a spatial frequency domain oxygenation imaging system. J Biomed Opt 2011;16(8):086015.

66. Pharaon MR, Scholz T, Bogdanoff S, Cuccia D, Durkin AJ, Hoyt DB, Evans GR. Early detection of complete vascular occlusion in a pedicle flap model using quantitative [corrected] spectral imaging. Plast Reconstr Surg 2010;126:1924-35.

67. Meier JK, Prantl L, Muller S, Moralis A, Liebsch G, Gosau M. Simple, fast and reliable perfusion monitoring of microvascular flaps. Clin Hemorheol Microcirc 2012;50:13-24.

68. Mueller S, Meier J-K, Wendl C-M, Jung EM, Prantl L, Gosau M. Mandibular reconstruction with micro- vascular re-anastomosed fibular free flaps-two complementary methods of postoperative transplant monitoring. Clin Hemorheol Microcirc 2012;52:141-51.

69. Stack BC Jr, Futran ND, Shohet MJ, Scharf JE. Spectral analysis of photoplethysmograms from radial forearm free flaps. Laryngoscope 1998;108:1329-33.

70. Stack Jr BC, Futran ND, Zang B, Scharf JE. Initial experience with personal digital assistant-based reflectance photoplethysmography for free tissue transfer monitoring. Ann Plast Surg 2003;51:136-40.

71. Whitney TM, Lineawearer WC, Billys JB, Siko PP, Buncke GM, Alpert BS, Oliva A, Buncke HJ. Improved salvage of complicated microvascular transplants monitored with quantitative fluorometry. Plast Reconstr Surg 1992;90:105-11.

72. Issing WJ, Naumann C. Evaluation of pedicled skin flap viability by $\mathrm{pH}$, temperature and fluorescein: an experimental study. J Craniomaxillofac Surg 1996;24:305-9.

73. Silverman DG, Cedrone FA, Hurford WE, Bering TG, LaRossa DD. Monitoring tissue elimination of fluorescein with the perfusion fluorometer: a new method to assess capillary blood flow. Surgery 1981;90:409-17.

74. Silverman DG, Kim DJ, Brousseau DA, Kim M, Norton KJ, Reilly CA. Fluorescence assessment of skin perfusion after oral fluorescein. Surgery 1988;103:221-5.

75. Rubben A, Eren S, Krein R, Younossi H, Bohler U, Wienert V. Infrared videoangiofluorography of the skin with indocyanine green rat random cutaneous flap model and results in man. Microvasc Res 1994;47:240-51.

76. Olivier WA, Hazen A, Levine JP, Soltanian H, Chung S, Gurtner GC. Reliable assessment of skin flap viability using orthogonal polarization imaging. Plast Reconstr Surg 2003;112:547-55.

77. Erdmann D, Sweis R, Wong MS, Eyler CE, Olbrich KC, Levin LS, Germann G, Klitzman B. Current perspectives of orthogonal polarization spectral imaging in plastic surgery. Chirurg 2002;73:827-32.

78. Tsuchida Y. Age-related changes in skin blood flow at four anatomic sites of the body in males studied by xenon-133. Plast Reconstr Surg 1990;85:556-61.

79. Rival R, Bance M, Antonyshyn O, Phillips J, Pang CY. Comparison of laser Doppler flowmeter and radioactive microspheres in measuring blood flow in pig skin flaps. Layngoscope 1995;105:383-6.

80. Hiortdal VE, Hansen ES Henriksen TB, Kjolseth D, Soballe K, Djurhuus $J C$. The microcirculation of myocutaneous island flaps in pigs studied with radioactive blood volume tracers and microspheres of different sizes. Plast Reconstr Surg 1992;89:116-22.

81. Hendel PM, Lilien DL, Buncke HJ. A study of the pharmacologic control of blood flow to acute skin flaps using xenon washout. Part I. Plast Reconstr Surg 1983;71:387-98.

82. Hendel PM, Lilien DL, Buncke HJ. A study of the pharmacologic control of blood flow to delayed skin flaps using xenon washout. Part II. Plast Reconstr Surg 1983;71:399-407.

83. Milstein DM, Lindeboom JA, Ince C. Intravital sidestream dark-field (SDF) imaging is used in a rabbit model for continuous noninvasive monitoring and quantification of mucosal capillary regeneration during wound healing in the oral cavity: a pilot study. Arch Oral Biol. 2010;55:343-9.

84. Hardwicke JT, Bella H, Waters RA. Sidestream Dark Field imaging as an adjunct to free flap monitoring. J Plast Reconstr Aesthet Surg 2014;67:875-7.

85. Yuen JC, Feng Z. Monitoring free flaps using the laser Doppler flowmeter: five-year experience. Plast Reconstr Surg 2000;105:55-61.

86. Jenkens S, Sepka R, Barwick W, Serafin D, Klitzam B. Routine clinical use of laser doppler flowmeter to monitor free tissue transfer: preliminary results. J Reconstr Microsurg 1987;3:281-3.

87. Hallock GG. Physiological studies using laser Doppler flowmetry to compare blood flow to the zones of the free TRAM flap. Ann Plast Surg 2001;47:229-33. 
88. Svensson H, Pettersson H, Svedman P. Laser Doppler flowmetry and laser photometry for monitoring free flaps. Scand J Plast Reconstr Surg 1985;19:245-9.

89. Cornejo A, Rodriguez T, Steigelman M, Stephenson S, Sahar D, Cohn SM, Michalek JE, Wang HT. The use of visible light spectroscopy to measure tissue oxygenation in free flap reconstruction. J Reconstr Microsurg 2011;27:397-402.

90. Fox PM, Zeidler K, Carey J, Lee GK. White light spectroscopy for free flap monitoring. Microsurgery 2013;33:198-202.

91. Ozturk CN, Ozturk C, Ledinh W, Bozkurt M, Schwarz G, O'Rourke C Djohan R. Variables affecting postoperative tissue perfusion monitoring in free flap breast reconstruction. Microsurgery 2015;35:1238.

92. Thorniley MS, Sinclair JS, Barnett NJ, Shurey CB, Green CJ. The use of near-infrared spectroscopy for assessing flap viability during reconstructive surgery. Br J Plast Surg 1998;51:218-26.

93. Steele $\mathrm{MH}$. Three year experience using near infrared spectroscopy tissue oximetry monitoring of free tissue transfers. Ann Plast Surg 2011;66:540-5.

94. Whitaker IS, Pratt GF, Rozen WM, Cairns SA, Barrett MD, Hiew LY Cooper MA, Leaper DJ. Near infrared spectroscopy for monitoring flap viability following breast reconstruction. J Reconstr Microsurg 2012;28(3):149-54.

95. Lohman RF, Langevin CJ, Bozkurt M, Kundu M, Djohan R. A prospec tive analysis of free flap monitoring techniques: physical examination, external Doppler, implantable Doppler, and tissue oximetry. J Reconstr Microsurg 2013;29:51-6.

96. Khater AM, Doi K, Hattori Y, Sakamoto S, Yonemura H, Kumar K. The use of compound muscle action potentials (CMAP) for postoperative monitoring of free functioning gracilis muscle transfer: A preliminary report. J Plast Reconstr Aesthet Surg 2015;68:e137-46.

97. Arnander C, Larsson L. Excitability in free muscle transfers: an optimal method of monitoring tissue circulation? Ann Plast Surg 1986;17:475-9.

98. Eren S, Krein R, Hafemann B. Objective evaluation of the microcirculation in the skin with indocyanine green angiography (ICGA). A method for the clinic? Handchir Mikrochir Plast Chir 1995;27:307-14.

99. Eren S, Rubben A, Krein R, Larkin G, Hettich R. Assessment of microcirculation of an axial skin flap using indocyanine green fluorescence angiography. Plast Reconstr Surg 1995;96:1636-49.

100. Swartz WM, Izquierdo R, Miller MJ. Implantable venous Doppler microvascular monitoring: laboratory investigation and clinical results. Plast Reconstr Surg 1994;93:152-63.

101. Swartz WM, Jones NF, Cherup LL, Klein A. Direct monitoring of microvascular anastomoses with the $20 \mathrm{MHz}$ ultrasonic Doppler probe: an experimental and clinical study. Plast Reconstr Surg 1988;81:149-61.

102. Banis JC Jr, Schwartz KS, Ackland RD. Electromagnetic flowmetry -an experimental method for continuous blood flow measurement using a new island flap model. Plast Reconstr Surg 1980;66:534-44.

103. Nigra CA. Electromagnetic blood flowmetry. Plast Reconstr Surg 1981;68:647.

104. Matsumine $H$, Mogami M, Fujiwara O, Hasegawa $M$, Ito $H$, Sakura $\mathrm{H}$. Improvement of the salvage-rate of flap after venous thrombosis with inraparenchymatous venous pressure monitoring. Microsurgery 2018;38:498-503.

105. May FW, Halls MJ. Thermocouple probe monitoring for the tissue transfer, replantation and revascularisation procedures Clin Plast Surg 1985;12:197-207.

106. May JW Jr, Lukash FN, Gallico GG 3rd, Stirrat CR. Removable thermocouple probe microvascular patency monitor: an experimental and clinical study. Plast Reconstr Surg 1983;72:366-79.

107. Concannon MJ, Stewart DH, Welsh CF, Puckett CL. Impedance plethysmography: a new method for continuous muscle perfusion monitoring. Plast Reconstr Surg 1991;88:292-8.

108. Larsson L. An electrophysiological method for monitoring blood flow in skeletal muscle. An experimental study in the rat. Scand J Plast Reconstr Surg Hand Surg 1989;23:181-6.

109. Machens HG, Mailaender $P$, Reimer R, Pallua N, Lei Y, Berger A. Postoperative blood flow monitoring after free-tissue transfer by means of the hydrogen clearance technique. Plast Reconstr Surg 1997;99:493-505.

110. Thomson JG, Karrigan CL. Hydrogen clearance: assessment of technique for measurement of skin-flap blood flow in pigs. Plast Reconstr Surg 1991;88:657-63.
111. Schrey AR, Kinnunen IA, Grénman RA, Minn H, Vahlberg T, Kalliokoski K, Suominen E, Grénman R, Aitasalo K. Monitoring microvascular free flaps with tissue oxygen measurement and PET. Eur Arch Otorhinolarynol 2008;265(Suppl 1):S105-13.

112. Roger ML, Brennan PA, Leong CL, Gowers SA, Aldridge T, Mellor TK, Boutelle MG. Online rapid sampling microdialysis (rsMD) using enzyme-based electroanalysis for dynamic detection of ischemia during free flap reconstructive surgery. Anal Bioanal Chem 2013;405:3881-8

113. Setälä LP, Korvenoja EM, Härmä MA, Alhava EM, Uusaro AV Tehhunen JJ. Glucose, lactate, and pyruvate response in an experimental model of microvascular flap ischemia and reperfusion: a microdialysis study. Microsurgery 2004;24:223-31.

114. Dickson MG, Sharpe DT. Continuous subcutaneous tissue pH measurement as a monitor of blood flow in skin flaps: an experimental study. Br J Plast Surg 1985;38:39-42.

115. Zeeshan A, Swan MC, Flynn M, Khan MS. The Histamine reaction: A Usefull Adjunct for Monitoring Free Flaps. Plast Reconstr Surg 2011;127:85e-7e.

116. Neumeister MW. Free flap monitoring: keeping it simple and reliable. Plast Reconstr Surg 2006;117:1073-4.

117. Busic V, Das-Gupta R. Temperature monitoring in free flap surgery. Br J Plast Surg 2004;57:588.

118. Bradford CR. Flap monitoring. Facial Plast Surg 1996;12:19-21.

119. Hitchinson CR, Williams KD. Postoperative free flap monitoring: clinical guidelines. British Association of Head and Neck Oncology Nurses, Bristol, 2000

120. Sekido M, Yamamoto Y, Sugihara T. Arterial blood flow changes after free tissue transfers in head and neck reconstruction. Plast Reconstr Surg 2005; 115:1547-52.

121. Cotter CJ, Devine JC. Spatula bruises and monitoring of free flaps. Br J Oral Maxillofac Surg 2005;43:343-4.

122. Brown JS, Devine JC, Magennis P, Sillifant $P$, Rogers SN, Vaughan ED. Factors that influence the outcome of salvage in free tissue transfer. Br J Oral Maxillofac Surg 2003;41:16-20.

123. Bui DT, Cordeiro PG, Hu QY, Disa JJ, Pusic A, Mehrara BJ. Free flap reexploration: indications, treatment, and outcomes in 1193 free flaps. Plast Reconstr Surg 2007;119:2092-100.

124. Gill PS, Hunt JP, Guerra AB, Dellacroce FJ, Sullivan SK, Boraski J, Metzinger SE, Dupin CL, Allen RJ. A 10-year retrospective review of 758 DIEP flaps for breast reconstruction. Plast Reconstr Surg 2004;113:1153-60.

125. Khouri RK, Cooley BC, Kunselman AR, Landis JR, Yeramian P, Ingram D, Natarajan N, Benes CO, Wallemark C. A prospective study of microvascular free-flap surgery and outcome. Plast Reconstr Surg 1998;102:711-21

126. Kroll SS, Schusterman MA, Reece GP. Timing of pedicle thrombosis and flap loss after free-tissue transfer. Plast Reconstr Surg 1996;98:1230-3.

127. Nakatsuka T, Harii K, Asato H, Takushima A, Ebihara S, Kimata $Y$, Yamada A, Ueda K, Ichioka S. Analytic review of 2372 free flap transfers for head and neck reconstruction following cancer resection. J Reconstr Microsurg 2003;19:363-9.

128. Smit JM, Werker PM, Liss AG, Enajat M, de Bock GH, Audolfsson T, Acosta R. Introduction of the implantable Doppler system did not lead to an increased salvage rate of compromised flaps: a multivariate analysis. Plast Reconstr Surg 2010;125:1710-7.

129. Abdel-Galil K, Mitchell D. Postoperative monitoring of microsurgical free tissue transfers for head and neck reconstruction: a systematic review of current techniques - Part I. Non-invasive techniques. $\mathrm{Br} J$ Oral Maxillofac Surg 2009;47:351-5.

130. Whitaker IS, Gulati V, Ross GL, Menon A, Ong TK. Variations in the postoperative management of free tissue transfers to the head and neck in the United Kingdom. Br J Oral Maxillofac Surg 2007;45:16-8.

131. Whitaker IS, Oliver DW, Ganchi PA. Postoperative monitoring of microvascular tissue transfers: current practice in the United Kingdom and Ireland. Plast Reconstr Surg 2003;111:2118-9.

132. Acland RD. Discussion of "experience in monitoring the circulation in free flap transfer". Plast Reconstr Surg 1981;68:554-5.

133. Kraemer R, Lorenzen J, Knobloch K, Papst S, Kabbani M, Koennecker $\mathrm{S}$, Vogt PM. Free flap microcirculatory monitoring correlates to free flap temperature assessment. J Plast Reconstr Aesthet Surg 2011;64:1353-8.

134. Abdel-Galil K, Mitchell D. Postoperative monitoring of microsurgical free-tissue transfer for head and neck reconstruction: a systematic 
review of current techniques-Part II. Invasive techniques. $\mathrm{Br} J$ Oral Maxillofac Surg 2009;47:438-42.

135. De la Torre J, Heden W, Grant 3rd JH, Gardner PM, Fix RJ. Vasconez LO. Retrospective review of the internal Doppler probe for intra and postoperative microvascular surveillance. J Reconstr Microsurg 2003;19:287-90.

136. Tsuzuki K, Yanai A, Bandoh Y. A contrivance for monitoring skin flaps with a Doppler flowmeter. J Reconstr Microsurg 1990;6:363-6.

137. Unadkat JV, Rothfuss M, Mickle MH, Sejdic E, Gimbel ML. The Development of a Wireless Implantable Blood Flow Monitor. Plast Reconstr Surg 2015;136:199-203.

138. Oliver DW, Whitaker IS, Giele H, Critchley P, Cassell O. The CookSwartz venous Doppler probe for the post-operative monitoring of free tissue transfer in the United Kindgom: a preliminary report. Br J Plast Surg 2005;58:366-70.

139. Haerten R, Lowery C, Becker G. "Ensemble Tissue Harmonic Imaging", Technologie und klinischer Nutzen. Electromedia 1999;67:56-62.

140. Figus A, Mosahebi A, Ramakrishnan V. Microcirculation in DIEP flaps: a study of the haemodynamics using laser Doppler flowmetry and lightguide reflectance spectrophotometry. J Plast Reconstr Aesthet Surg 2006;59:604-13.

141. Ribuffo D, Muratori L, Antoniadou K, Fanini F, Martelli E, Marini M, Messineo D, Trinci M, Scuderi N. A hemodynamic approach to clinical results in the TRAM flap after selective delay. Plast Reconstr Surg 1997;99:1706-14.

142. Salmi AM, Tukiainen E, Asko-Seljavaara S. Thermographic mapping of perforators and skin blood flow in the free transverse rectus abdominis musculo-cutaneous flap. Ann Plast Surg 1995;35:159-64.

143. Tuominen HP, Asko-Seljavaara S, Svartling NE. Cutaneous blood flow in the free TRAM flap. Br J Plast Surg 1993;46:665-9.

144. Yanaga H, Tai Y, Kiyokawa K, Inoue Y, Rikimaru H. An ipsilateral superdrainaged transverse rectus abdominis myocutaneous flap for breast reconstruction. Plast Reconstr Surg 1999;103:465-72.

145. Goldberg J, Sepka RS, Perona BP, Pederson WC, Klitzman B. Laser Doppler blood flow measurements of common cutaneous donor sites for reconstructive surgery. Plast Reconstr Surg 1990;85:581-6.

146. Mucke T, Rau A, Merezas A, Loeffelbein DJ, Wagenpfeil S, Mitchel DA, Wolff KD, Steiner T. Identification of perioperative risk factor by laser-Doppler spectroscopy after free flap perfusion in the head and neck: a prospective clinical study. Microsurgery 2014;34:345-51.

147. Rothenberger J, Amr A, Schaller H-E, Rahmanian-Schwartz A Evaluation of a non-invasive monitoring method for free flap breast reconstruction using laser Doppler flowmetry and tissue spectrophotometry. Microsurgery 2013;33:350-7.

148. Lee SY, Pakela JM, Hedrick TL, Vishwanath K, Helton MC, Chung Y Kolodziejski NJ, Stapels CJ, McAdams DR, Fernandes DE, Christian J, O'Reilly J, Farkas D, Ward BB, Feinberg SE, Mycek MA. Novel diffuse optics system for continuous tissue viability monitoring - extended recover in vivo testing in a porcine flap model. Proc SPIE Int Soc Opt Eng 2017;10054:1005413.

149. Pakela JM, Lee SY, Hedrick TL, Vishwanath K, Helton MC, Chung YG, Kolodziejski N, Stapels CH, McAdams DR, Frenandes DE, Christian JF O'Reilly J, Farkas D, Ward BB, Feinberg E, Mycek MA. In vivo preclinical verification of a multimodal diffuse reflectance and correlation spectroscopy system for sensing tissue perfusion. Proc SPIE Int Soc Opt Eng 2017;10072:100720U.

150. Lin SJ, Nguyen MD, Chen C, Colakoglu S, Curtis MS, Tobias AM, Lee BT. Tissue oximetry monitoring in microsurgical breast reconstruction decreases flap loss and improves rate of flap salvage. Plast Reconstr Surg 2011;127:1080-5.

151. Achauer BM, Black KS, Beran AV, Huxtable RF. Transcutaneous PO2 monitoring of flap circulation following surgery. Birth Defects Orig Artic Ser 1979;15:517-22.

152. Achauer BM, Black KS, Litke DK. Transcutaneous PO2 in flaps: a new method of survival prediction. Plast Reconstr Surg 1980;65:738-45.

153. Hashimoto I, Nakanishi H, Takiwaki H, Takase MT, Yamano M, Sedo $\mathrm{H}$. Flap monitoring by transcutaneous PO2 and PCO2: importance for transcutaneous PCO2 in determining follow-up treatment for compromised free flaps. J Reconstr Microsurg 2007;23:269-74.

154. Jonas R, Schael T, Krimmel M, Gülicher D, Reinert S, Hoffmann J. Monitoring in microvascular tissue transfer by measurement of oxygen partial pressure: four years experience with 125 microsurgical transplants. J Craniomaxillofac Surg 2013;41:303-9.

155. Prasetyono TO, Adianto S. The relationship between oxygen satura- tion and color alteration of a compromised skin flap: experimental study on the rabbit. Arch Plast Surg 2013;40:505-9.

156. McCraw JB, Myers B, Shanklin KD. The value of fluorescein in predicting the viability of arterialised flaps. Plast Reconstr Surg 1977;60:710-9.

157. Denneny JC 3rd, Weisman RA, Silverman DG. Monitoring free flap perfusion by serial fluorometry. Otolaryngol Head Neck Surg 1983;91:372-6.

158. Mothes $H$, Donicke T, Friedel R, Simon M, Markgraf E, Bach O. Indocyanine-green fluorescence video angiography used clinically to evaluate tissue perfusion in microsurgery. J Trauma 2004;57:1018-24.

159. Nagata T, Masumoto K, Uchiyama Y, Watanabe Y, Azuma R, Morimoto $Y$, Katou F. Improved technique for evaluating oral free flaps by pinprick testing assisted by indocyanine green near-infrared fluorescence angiography. J Craniomaxillofac Surg 2014;42:1112-6.

160. Aygit AC, Sarikaya A. Technetium $99 \mathrm{~m}$ sestamibi scintigraphy for noninvasive assessment of muscle flap viability. Ann Plast Surg 1999;43:338-40.

161. Top H, Sarikaya A, Aygit AC, Benlier E, Kiyak M. Review of monitoring free muscle flap transfers in reconstructive surgery: role of $99 \mathrm{mTc}$ sestamibi scintigraphy. Nucl Med Commun 2006;27:91-8.

162. Lee I, Kang SY, Heo CY, Lee HY, Kim SE. Evaluation of flap tissue viability by F-18 FDG PET/CT. Nucl Med Mol Imaging 2014;48:241-3.

163. Jiränki J, Suominen S, Vuola J, Bäck L. Microdialysis in clinical practice: monitoring intraoral free flaps Ann Plast Surg 2006;56:387-93.

164. Brueggemann A, Noltze A, Lange T, Kaun M, Gliemroth J, Goerg S, Bahlmann L, Klaus S, Siemers F, Mailaender P, Machens HG. Significant $(\mathrm{C} 3 \mathrm{a})$ increase in free flaps after prolonged ischemia. J Surg Res 2008;150:125-30.

165. Ionac M, Schaefer D, Geishauser M. Thromboxane A2 release in ischemia and reperfusion of free flaps in rats, studied by microdialysis. J Reconstr Microsurg 2001;17:139-43.

166. Edsander-Nord A, Rojdmark J, Wickman M. Metabolism in pedicled and free TRAM flaps: a comparison using the microdialysis technique. Plast Reconstr Surg 2002;109:664-73.

167. Henault B, Pluvy I, Pauchot J, Sinna R, Labruere-Chazai C, Zwetyenga N. Capillary measurement of lactate and glucose for free flap monitoring. Ann Chir Plast Esthet 2014;59:15-21.

168. Hara H, Mihara M, lida T, Narushima M, Todokoro T, Yamamoto T, Koshima I. Blood glucose measurement for flap monitoring to salvage flaps from venous thrombosis. J Plast Reconstr Aesthet Surg 2012;65:616-9.

169. Hara H, Mihara M, lida T, Narushima M, Koshima I. Blood glucose measurement in flap monitoring for salvage of flaps from venous thrombosis. Plast Reconstr Surg 2012;129:587e-9e.

170. Hara H, Mihara M, Narushima M, Yamamoto T, Todokoro T, Araki J, lida T, Koshima I, Shim TW. Flap salvage following postoperative venous thrombosis diagnosed by blood glucose measurement in the flaps. Eplasty 2011;11:e28.

171. Dunn RM, Kaplan IB, Mancoll J, Terzis JK, Trengove-Jones G. Experimental and clinical use of $\mathrm{pH}$ monitoring of free tissue transfers. Ann Plast Surg 1993;31:539-45.

172. Hwang $\mathrm{JH}$, Mun GH. An evolution of communication in postoperative free flap monitoring: using a smartphone and mobile messenger application. Plast Reconstr Surg 2012;130:125-9.

173. Engel H, Huang JJ, Tsao CK, Lin CY, Chou P, Brey EM, Henry SL, Cheng $\mathrm{MH}$. Remote real-time monitoring of free flaps via smartphone photography and $3 \mathrm{G}$ wireless Internet: a prospective study evidencing diagnostic accuracy. Microsurgery 2011;31:589-95.

174. Kim SH, Shin HS, Lee SH. "Internet of Things" Real-Time Free Flap Monitoring. J Craniofac Surg 2018;29:e22-5.

175. Liu YF, Vuong C, Walker PC, Peterson NR, Inman JC, Filho PA, Lee SC. Noninvasive free flap monitoring using Eulerian Video Magnification. Case Rep Otolaryngol 2016:9471696.

176. Gardiner S, Hartzell TL. Telemedicine and plastic surgery: a review of its applications, limitations and legal pitfalls. J Plast Reconstr Aesthet Surg 2012;65:e47-53.

177. Creech B, Miller S. Evaluation of circulation in skin flaps. In: Grabb WC, Myers MB, eds. Skin flaps. Boston, MA: Little, Brown; 1975:21-38.

178. Stranix JT, Jacoby A, Lee ZH, Anzai L, Saadeh PB, Thanik V, Levine JP. Skin Paddles Improve Muscle Flap Salvage Rates After Microvascular Compromise in Lower Extremity Reconstruction. Ann Plast Surg 2018;81:68-70. 
179. Marsh M, Elliott S, Anand R, Brennan PA. Early postoperative care for free flap head and neck reconstructive surgery - a national survey of practice. Br J Oral Maxillofac Surg 2009;47:182-5.

180. Devine JC, Potter LA, Magennis P, Brown JS, Vaughan ED. Flap monitoring after head and neck reconstruction: evaluation an observation protocol. J Wound Care 2001;10:525-9.

181. Hung MJ, Hu P, Hung MY. Coronary Artery Spasm: Review and Update. Int J Med Sci 2014;11:1161-71.

182. Nazir H, Lowe D, Rogers S-N. Patient's experience of the monitoring of free flaps after reconstruction for oral cancer. Br. J Oral Maxillofac Surg 2017;55:1008-12.

183. Salgado CJ, Moran SL, Mardini S. Flap monitoring and patient management. Plast Reconstr Surg 2009;124(6 Suppl):e295-302.

184. Poder TG, Fortier PH. Implantable Doppler in monitoring free flaps: a cost-effectiveness analysis based on systematic review of the literature. Eur Ann Otorhinolaryngol Head Neck Dis 2013;130:79-85.

185. Subramaniam S, Sharp D, Jardim C, Batstone MD. Cost-effectiveness of monitoring free flaps. Br Journal of Oral and Maxillofacial Surg 2016;54:579-83. 